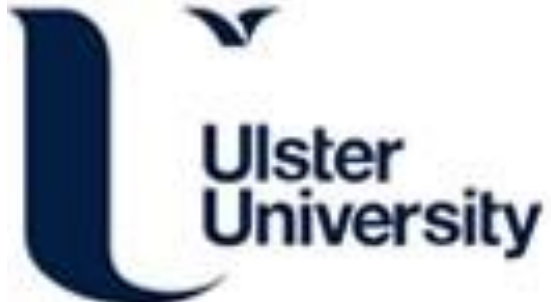

\section{Access to Justice through University Law Clinics}

Drummond, O., \& McKeever, G. (2015). Access to Justice through University Law Clinics. School of Law, Ulster University. http://www.ulster.ac.uk/lawclinic/files/2014/06/Access-to-Justice-through-Uni-Law-Clinics-November2015.pdf

Link to publication record in Ulster University Research Portal

Publication Status:

Published (in print/issue): 01/11/2015

\section{Document Version}

Publisher's PDF, also known as Version of record

\section{General rights}

Copyright for the publications made accessible via Ulster University's Research Portal is retained by the author(s) and / or other copyright owners and it is a condition of accessing these publications that users recognise and abide by the legal requirements associated with these rights.

\section{Take down policy}

The Research Portal is Ulster University's institutional repository that provides access to Ulster's research outputs. Every effort has been made to ensure that content in the Research Portal does not infringe any person's rights, or applicable UK laws. If you discover content in the Research Portal that you believe breaches copyright or violates any law, please contact pure-support@ulster.ac.uk. 
Ulster University

\section{Access to Justice through University Law Clinics}

By Orla Drummond and Gráinne McKeever

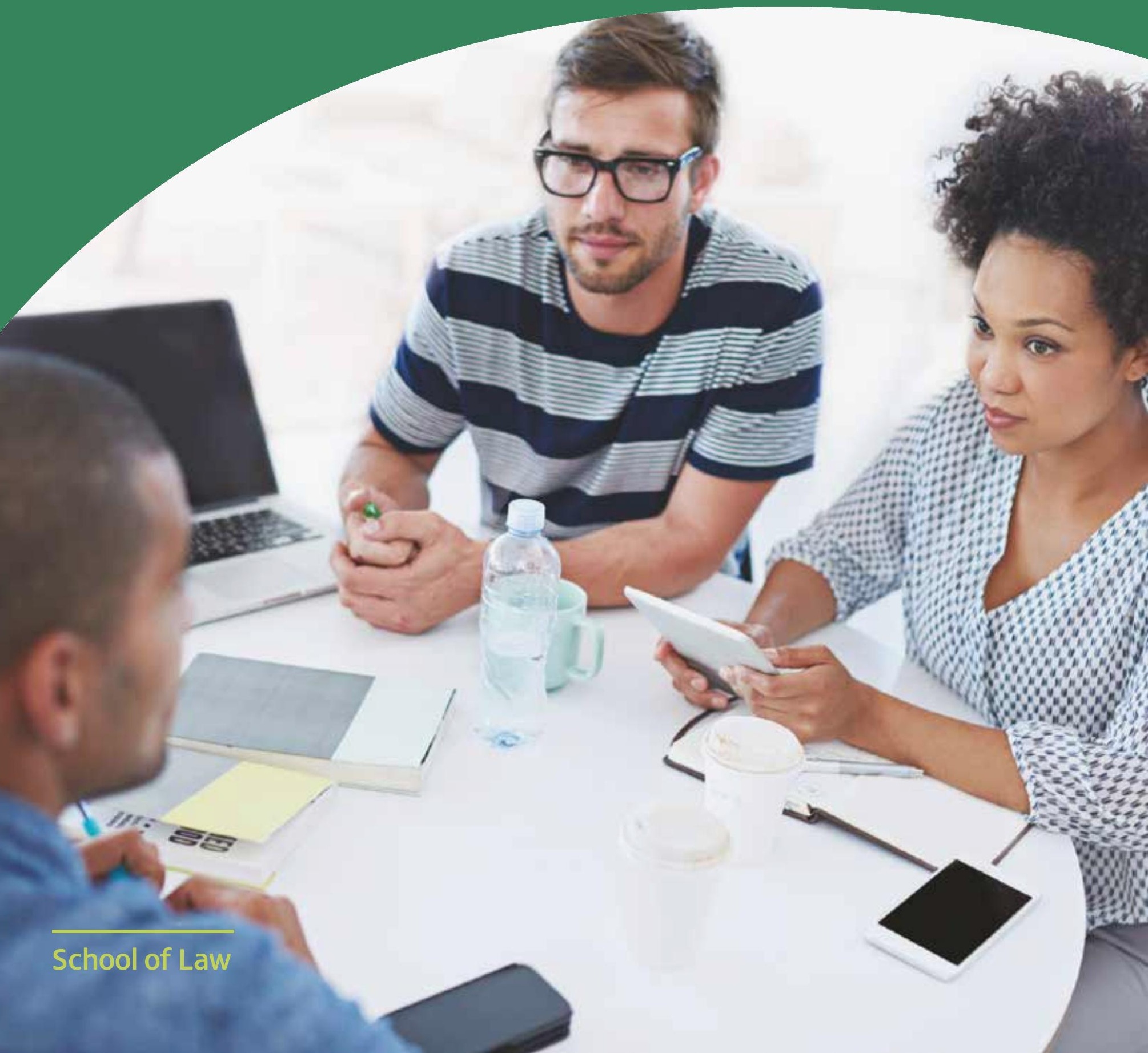




\section{Acknowledgements}

The research for this report was funded by the Legal Education Foundation and the authors are extremely grateful to the Foundation for this support. The authors acknowledge also the contribution of colleagues in the School of Law, Ulster University, who provided valuable insight and support throughout the research and writing process. In particular, we wish to thank Dr John McCord, Dr Eugene McNamee, Dr Esther McGuinness and Ciarán White who provided comments on drafts of this document and prompted our thinking. An early draft of this report has also benefited from review by external colleagues, including Colin Stutt, author of the Access to Justice Review 2, and Ursula O'Hare, Policy Director at Law Centre (NI), and we are grateful for their comments and expertise. Finally, we wish to acknowledge the contribution of university law clinic staff from Law Schools across the UK, who engaged fully with the project and whose enthusiasm for the clinic movement provided us with the encouragement to develop the research. The responsibility for any errors in the research remain those of the authors.
Access to Justice through University Law Clinics ISBN: 978-1-85923-268-2

Published in October 2015 by Ulster University Law School with support from The Legal Education Foundation 


\section{Contents}

Acknowledgements

The authors

Executive summary

Findings

Recommendations

Part 1: Integrating access to justice

and legal education $\quad 7$

Introduction $\quad 8$

Access to justice $\quad 8$

The vulnerability to legal problems $\quad 8$

Responses to legal problems

Citizen engagement in dispute resolution $\quad 9$

\begin{tabular}{ll} 
Seeking advice & 9 \\
\hline A focus on state funding & 10
\end{tabular}

A focus on state funding $\quad 10$

Other solutions 11

Clinical Legal Education $\quad 12$

CLE and social justice 12

The marketisation of higher education $\quad 13$

Resourcing CLE $\quad 13$

Conclusion 14

Part 2 - CLE survey analysis and findings $\quad 15$

$\begin{array}{lr}\text { Methodology } & 15 \\ \text { Clinic profiles } & 16\end{array}$

\begin{tabular}{ll} 
Clinic profiles & 16 \\
\hline Areas of law covered & 17
\end{tabular}

Areas of law covered $\quad 17$

Clinic caseloads $\quad 18$

Connections with other service providers $\quad 19$

$\begin{array}{ll}\text { Client profiles } & 19 \\ \text { Case selection criteria } & 21\end{array}$

\begin{tabular}{ll} 
Case selection criteria & 21 \\
\hline Paths to the clinic & 22
\end{tabular}

\begin{tabular}{ll} 
Paths to the clinic & 21 \\
\hline Intervention points & 24
\end{tabular}

Intervention points $\quad 22$

Barriers to justice $\quad 25$

Intellectual barriers $\quad 25$

\begin{tabular}{ll} 
Practical barriers & 25 \\
\hline
\end{tabular}

Emotional barriers $\quad 26$

Awareness and perceptions of clinics $\quad 27$

Clinic objectives $\quad 28$

\begin{tabular}{ll} 
Conclusion & 38 \\
\hline
\end{tabular}

Part 3-Conclusions and recommendations $\quad 31$

The role of universities $\quad 32$

Delivering access to justice through universities $\quad 32$

Limitations of university law clinics as access

Development potential for clinics as access

to justice providers 34

Recommendations $\quad 35$

$\begin{array}{ll}\text { Conclusion } & 35 \\ \end{array}$ 


\section{Access to Justice through University Law Clinics}

\section{The authors}

Dr Orla Drummond is a Research Assistant in the School of Law, Ulster University.

Dr Gráinne McKeever is a Reader in Law in the School of Law, Ulster University and a Director of the Ulster University Law Clinic. She is also a member, and former Chair, of Law Centre (NI) and a member of the Social Security Advisory Committee. This report is written in her capacity as a Reader in Law and the views expressed within the report should not be taken to be those of Law Centre (NI) or the Social Security Advisory Committee. 


\section{Executive summary}

This report is based on data received through responses to an electronic survey which was distributed to university Law Schools throughout the UK from June-July 2015. The research identified 62 university Law Schools with law clinics, of whom 32 responded to the survey, giving a survey response rate of $52 \%$.

\section{Findings}

There has been an increase in the number of university law clinics from the 1990s, with an acceleration in development from 2000-10 and a further acceleration from 2011-15.

University Law Clinics vary in terms of staff and student profiles and numbers, indicating that they are usually bespoke creations to meet the needs defined by individual Law Schools.

Clinics cover a diverse range of legal areas, including housing, commercial, consumer, family, employment, health and social care, immigration, criminal, education, social security, asylum, human trafficking, property, probate and wills. 13 out of 22 clinics identified that they provided an advice-only service, and nine clinics provided advice and representation. Clinics carried an average (mean) caseload of 104 cases per year, although the median figure is 70, and the mode is 100 .

$84 \%$ of clinics identified an increase in demand for their services over the last three years, but only $64 \%$ of clinics registered an increase in their annual caseload. The increased caseload of clinics was determined by the clinic's ability to increase its staffing, rather than in response to increased demand.

$75 \%$ of clinic respondents collaborated with external partners on client cases, principally with solicitors, independent advice organisations and barristers, through a mixture of formal and informal arrangements. Clinics saw the value of collaboration in being able to enhance their casework supervision, expertise, and capacity, and in being able to extend clinic services. Clinics identified the value to external partners as increasing the capacity of publicly funded organisations to meet legal need and enhancing the corporate social responsibility values of private sector organisations.

There are extensive networks of relationships between clinics and other legal service providers, and the findings suggest that the stronger the relationship the more likely this was to benefit clinic clients.

Most clinics do not formally assess clients on their financial means, and only a minority of clinics collect financial data, but the majority of clinics state that their clients are of limited financial means. $25 \%$ of clinics limit their services based on financial need. For the majority of clinics, the educational value of the case is seen as being the most important reason to take a client's case, and financial need is regarded as something that is not relevant to an assessment of educational value. Clinics identified their need to balance the objective of meeting unmet legal need with not encroaching on the services offered by other legal service providers.

In practice, case selection criteria for clinics were based on pragmatic choices around complexity of the case, area of law, alternative sources of advice, staff expertise, student capacity and timescales. The strategic focus on what is required to meet the educational needs of the clinic students could override the principle of selecting cases on financial need.

There is good evidence of the public visibility and utility of law clinics as legal service providers and of their connections to other sources of help and support.

Clinic clients face similar barriers as the general population in accessing justice, but further research is needed to understand the role of law clinics in helping clients overcome these barriers.

Clinic clients generally have misperceptions about the service that clinics are able to offer, with the most common misperceptions relating to the limitations of clinic services. Only 3 clinics out of 31 said clients had concerns about relying on legal advice from law students.

Clinics have a range of objectives that they seek to meet, covering access to justice and legal education, but they prioritise the objectives of improving student employability and developing professional capacity in law students over assisting local communities and delivering access to justice.

$69 \%$ of clinics adopted the position that Law Schools should deliver access to justice, with the main reasons being that this was an important part of a Law School or university ethos and an important part of legal learning. of the $31 \%$ of clinics that stated a university Law School should not be an access to justice provider, there was a clear sense that a law clinic should prioritise education; that clinics do not have the necessary capacity and resources to be an access to justice provider; and that it was the state's responsibility to provide access to justice. Overwhelmingly, however, clinics considered themselves to be access to justice providers, with $90 \%$ of respondents stating that they were access to justice providers for the basic reason that they provided help to clinic clients in accessing justice. 


\section{Recommendations}

1. Understanding the value of clinic partnerships to external organisations and advisers will be a necessary part of assessing the role that clinics play within the advice ecosystem. Further research should be undertaken to assess the value of those partnerships to external providers.

2. The impact made by clinics on the intellectual, practical and emotional barriers experienced by individuals in their attempts to resolve their legal problems needs to be understood. Specific research with clinic clients should be conducted to measure the extent to which clinics are able to enhance the legal capability of their clients. This research should include a focus on the impact of clinics not being able to offer a full legal service to clients, and the consequential impact of any collaborative, referral or signposting arrangements that clinics put in place for clients.

3. Clinics do not adopt case selection policies that prioritise complex, strategic or test cases, and they are reliant on expert and specialist advisers to be able to progress these types of cases. The role of expert and specialist advice should be protected within the advice ecosystem to enable clinics to offer the most effective form of legal support to their clients.

4. The relationship between clinics and external service providers is of critical importance and should be enhanced. A mapping of service provision across the UK, which includes the services delivered by university law clinics, would assist in establishing how these services interact, the limitations and scope of service provision and the consequent gaps that exist. It would also provide further insight into the significance of law clinics as a proportion of overall advice provision.

5. University law clinics offer considerable potential to capture original empirical data and observe social phenomena that can be mined for research purposes and translated into policy impact. This research can be based on the casework of external partners, as well as clinic casework, but the capacity of external partners to feed into policy-focused consultations and research should be enhanced so that policy makers are able to benefit from this responsive analysis of access to justice barriers.

6. University law clinics also constitute a unique environment in which to test and develop innovative solutions to legal problems, that can draw on expertise in cognate areas within universities, from psychology, to philosophy, to communications, to design, to IT. Funding bodies, particularly those with an interest in access to justice or in the application of crossdisciplinary innovations to social problems, should identify funding streams designed to support pioneering research in these areas.

7. If universities are to play a role in developing the access to justice potential of their law clinics, there should be external support from government to enable universities to align their core activities with this role, and to receive appropriate recognition for their work. This could include reassessing the funding allocations for teaching clinical legal education, providing additional funding for enhanced employability outcomes, and creating REF-focused research initiatives to connect researchers to law clinics.

8. Justice departments could work directly with universities to support Law Schools in being able to offer law clinics in areas of legal need, through direct funding to university staff focused on casework supervision or development planning, or indirectly through funding student support to increase the ability of students to deliver casework.

9. University law clinics could also be supported by other government departments whose policies and practices may be contributing to increases in legal need, for example through regulatory changes to social security entitlements or special educational needs provision, particularly if clinic-focused research was designed to identify systematic improvements in decision-making processes.

10. While law clinics are split on whether their mission is to provide social justice or enhanced educational experiences, there is a recognition by clinics that their work does deliver access to justice for clients, and that students are part of this process of meeting access to justice needs. Further research should be conducted to establish the impact of law clinics on developing a social justice ethos among law students, and in particular on developing student attitudes towards pro bono activities as part of the role of lawyers. 


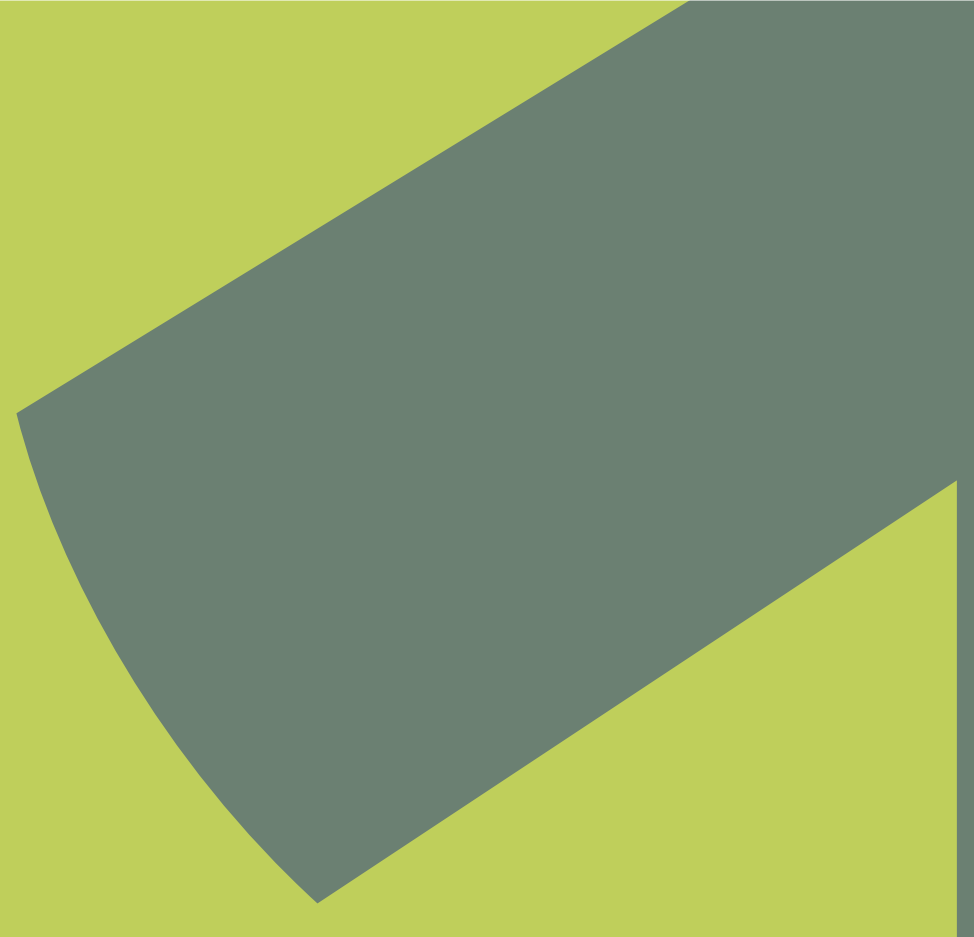

Part 1: Integrating

access to justice

and legal education 


\section{Part 1: Integrating access to justice and legal education}

\section{Introduction}

The role of the state in providing access to justice in the UK has undergone considerable change in the last 30 years, moving from a publicly funded legal aid system that was regarded as one of the most generous in the world, to a rationalised provision that has seen significant reductions to both the scope of work that comes within legal aid schemes and the remuneration available to cover it. The legal aid changes across the UK have not been uniform, with more rapid and drastic reductions in Britain than in Northern Ireland, but the same questions have been considered in all jurisdictions of what the state's role is in providing access to justice, how this role might be discharged, and what alternative provision might be made to ensure that citizens can continue to access justice. The need to look for innovative solutions to the difficulties people have in accessing justice is not prompted simply by a focus on funding, but by the need to respond to the nature, substance and extent of justiciable problems, and intellectual curiosity in exploiting the potential of new advances in education, technology, legal systems and other areas that impact on social and legal problems.

An understanding of how and why people interact with legal systems is a critical part of developing a response to the problems they face in doing so, and in evaluating the effectiveness of current support mechanisms. The evolution of advice services has been a necessary part of responding to new areas of legal need and improving the provision in more traditional areas. So too have changes in legal education, and the role of the legal academy has had a dual purpose here - in research, to understand how the legal system works from the perspective of those who use it, and in education, to provide students with better insight into how the law impacts on people's lives. The educative ambition here is to equip the next generation of lawyers with the contextual knowledge that they will need to develop responsive solutions to evolving or perennial legal problems. The means of realising such ambitions are multiple, but include providing students with practical experience of how the law works: a learning-by-doing approach to understanding the barriers to justice, and the student/lawyer role in helping to overcome those barriers. The development of this form of education also offers the advantage of providing an alternative, additional method of meeting legal need where the practical learning is based on students helping the public with their legal problems. However, the extent to which this form of legal support can be effective in meeting such need is unclear.

This research is focused on understanding the role of university law clinics in delivering access to justice, alongside the existing legal support providers - examining the relationship between clinics and other access to justice services, looking at the services that clinics provide, and the limitations and possibilities of delivering access to justice through university clinics. There is a need to understand not just the access to justice landscape but the higher education landscape within which clinics are situated, and to establish empirically how the relationship between these different elements operate. The report therefore begins with a brief analysis of the difficulties faced by individuals in accessing justice, and explores the trajectory of clinical legal education and its responsiveness to access to justice issues.

\section{Access to justice}

The literature on access to justice offers a rich insight into the nature of justiciable problems, the ability of individuals to respond to them, and the range of responses that are employed to manage justiciable problems. Much of our understanding of how people experience legal problems is derived from Genn's seminal 'paths to justice' research in 1999, which has led to a number of large-scale national 'legal needs' surveys of the public's experience of civil (i.e. non-criminal) legal problems. ${ }^{1}$ This includes the Northern Ireland Legal Needs Survey, conducted by Dignan in 2006; ${ }^{2}$ the English and Welsh Civil and Social Justice Survey, conducted from 2001 to 2009, and replaced in 2010 by the English and Welsh Civil and Social Justice Panel Survey to incorporate longitudinal data; ${ }^{3}$ and the Scottish Crime and Justice Survey which includes some basic data on civil justice problems in Scotland. ${ }^{4}$ The data from each of these surveys reveals a high incidence of justiciable problems within the general population, with over 30 per cent of the population in Northern Ireland, England and Wales experiencing one or more legal problems, and 23 per cent in Scotland, in the three years prior to the most recent surveys that were conducted in each jurisdiction.

\section{The vulnerability to legal problems}

The number of people experiencing civil legal problems is significant, particularly given the unfortunate fact that legal problems beget other legal problems, and that multiple sources of disadvantage interact to increase vulnerability to justiciable problems creating a cluster of inter-related, reinforcing and complex issues. Pleasence has identified a number of groups who are more susceptible to experiencing justiciable problems including lone parents, those with long standing ill-health and disability, those living in the rented housing sector, those living in high density housing, those aged between 25 and 44 , the unemployed, those on means tested benefits and those on very low incomes. ${ }^{5}$ In addition, these groupings intersect with different experiences that are influenced 
by gender, ethnicity and economic circumstances, ${ }^{6}$ with the result that socially excluded groups are particularly vulnerable to experiencing justiciable problems. ${ }^{7}$

Despite the prevalence of legal problems - which have remained at relatively consistent rates throughout the time span of the different legal needs surveys - not all individuals use the law to respond to these. The reasons for this can vary, and will be explored further, but this report takes as its starting point that individuals need to be able to interact with the legal system and to have access to meaningful legal redress. As Balmer states: "The ability of people to protect their legal rights and hold others to their legal responsibilities is a prerequisite of the rule of law and underpins social justice." ${ }^{8}$ The ability of individuals to navigate through the maze of different forms of legal redress - from courts and tribunals, to complaints and ombudsmen - is a critical element of access to justice but one that demands a certain level of legal capability from citizens. Collard et al define a legally capable individual as one who has the "knowledge, skills and attitudes to deal effectively with law-related issues." ${ }^{9}$ In their analysis, there are four domains of legal capability:

1. Recognising and framing the legal dimensions of issues and situations;

2. Finding out more about the legal dimensions of issues and situations;

3. Dealing with law-related issues and situations;

4. Engaging and influencing. ${ }^{10}$

Collard et al argue that a legally capable person will be able to deal sooner and better with an issue or situation, know when to seek expert advice and when to deal with an issue personally, thereby preventing a spiral of worsening problems. Yet numerous individuals experiencing justiciable issues lack many of these capability attributes. There is clear evidence from the literature that the problems experienced by the majority of citizens are not viewed by them through a legal lens, and so the vision of a legal solution may not be evident.

\section{Responses to legal problems}

The social and financial vulnerability experienced by individuals also has a bearing on their response to legal problems, not just the acquisition of those problems. Balmer et al highlight the division between differing socio-economic groups in their response to justiciable problems, with more affluent, educated respondents more likely to be aware of their rights and disadvantaged groups less likely to have knowledge of their rights and legal processes. ${ }^{11}$ In particular they highlight that women, those with mental health issues, those possessing no academic qualifications and those with long-term illness or with a disability were less likely to be aware of their rights or the processes associated with resolving their problems. $^{12}$

The most recent, in-depth analysis of the Civil and Social Justice Survey Panel Survey for England and Wales shows that problem resolution behaviour is unequivocally tied to legal capability. ${ }^{13}$ Those with high levels of legal capability, who understand their problems and/or rights to have a legal character are more likely to take action, while a "significant minority of cases of inaction are characterised by helplessness and powerlessness",14 leading to what Sandfeur describes as "frustrated resignation"15. This lack of legal capability means that people struggle with legal processes, are unsure of how to gain meaningful advice, or how to pursue legal remedies. ${ }^{16}$

\section{Citizen engagement in dispute resolution}

In Collard et al's conceptualisation of a legally capable individual, advice-seeking behaviour will be evident at a relatively early stage in the life of the legal problem. The advantages of getting advice early are based on the ability to prevent the problem worsening and/or acquiring related problems, and it is on this, understandable logic that advice services are often designed. Early intervention can often be a policy priority in an access to justice strategy, as a positive and efficient means of facilitating a legal resolution for an individual. In Susskind's analogy, the preference is for a fence at the top of the cliff rather than an ambulance at the bottom. ${ }^{17}$

There is no argument against the notion that prevention is better than cure, but individuals - and particularly those lacking legal capacity - tend not to seek help at the preventative stage, but rather at crisis point. In these cases, early intervention is when the individual recognises the crisis and acts in response: the 'early' corresponds to the earliest point at which an individual is ready or able to seek help and engage with legal processes. ${ }^{18}$ Their engagement may not always be successful, in part because problems may have become entrenched and are

P. Pleasence (n 5) p. 29-50

7. P. Pleasence ( $n$ 5) p. 74

N.J. Balmer, English and Welsh Civil and Social Justice Panel Survey: Wave 2 (Legal Services Commission, 2013) p. I, available at: http://doc.ukdataservice.ac.uk/doc/7643/mrdoc/pdf/7643_csjps_wave

two_summary_findings.pdf [accessed 9 October 2015]

S. Collard, C. Deeming, L. Wintersteiger, M. Jones and J. Seargeant, Public Legal Education Evaluation Framework (University of Bristol Personal Finance Research

Centre, 2011) p. 3

S. Collard et al (n 9) p. 4

${ }^{11}$ N.J. Balmer, A. Buck, A. Patel, C. Denvir and P. Pleasence, Knowledge, capability and the experience of rights problems (Legal Services Research Centre, 2010) p. 30

N.J. Balmer et al (n 11) p. 30

P. Pleasence and N.J. Balmer ( $\mathrm{n} 3$ )

${ }_{14}$ P. Pleasence and N.J. Balmer (n 3$)$ p. 3

${ }^{15}$ R.L. Sandefur, 'The importance of doing nothing: everyday problems and responses of inaction', in P Pleasence, A Buck and N.J. Balmer (eds), Transforming lives: law and social process, (Stationery

Office, Norwich 2007). See also S. Forell, E. McCarron \& L. Schetzer, No home, no justice? The legal needs of homeless people in NSW (Law and Justice Foundation of NSW, Sydney 2005) P. Pleasence

(n 5); N.J. Balmer et al (n 11)

N. J. Balmer et al (n 11) p. 8

R. Susskind, The End of Lawyers? Rethinking the nature of legal services, (Oxford University Press 2009)

${ }^{18} \mathrm{~S}$. Forrell, 'Is early intervention timely?' (2015) 20 Justice Issues 1-13 
more difficult to resolve, but also because legal systems are not always able to engage users. Empirical evidence on the experiences of tribunal users, for example, indicates that there are a number of intellectual, practical and emotional barriers that can block the individual's ability to participate effectively in decision making and dispute resolution processes. ${ }^{19}$ Intellectual barriers include those that prevent the user from understanding that there is a legal issue to be resolved; practical barriers include the difficulties experienced by users in identifying and securing relevant support and assistance; and emotional barriers include the stresses users face in engaging with unfamiliar and adversarial processes. What is also evident is that good quality support can help users overcome these barriers, creating a circular relationship between legal capacity and participation.

\section{Seeking advice}

When individuals do seek help with their legal problems the research highlights that help is sought from a broad range of sources, further emphasising the point that those with 'legal' problems may not see them as 'legal', and so are not singularly focused on legally-based solutions. ${ }^{20}$ Where legal advice is considered necessary, however, there remain a number of barriers in place to secure that advice. Pleasence and Balmer look specifically at the issue of cost as a characteristic of response to legal problems and their analysis reveals that:

"Where legal aid is most available, there appears to be a 'U' shaped relationship between income and lawyer use. Where no legal aid is available, there is a simpler relationship, with access increasing along with income; except where conditional/contingent fees (or an equivalent form of alternative payment mechanism) are available, in which case there appears to be no relationship." ${ }^{21}$

The issue of legal costs - or the perception of legal costs is revealed as a consideration in advice-seeking behaviour, with $57 \%$ of respondents to the Civil and Social Justice Survey Panel Survey who received help from an advice agency rather than a lawyer doing so because of the cost, or perceived cost, of instructing a private practice lawyer. ${ }^{22}$ Not all advice seeking behaviour is rationally constructed, however:

"As Pleasence et al. (2004, p.69-70) have observed 'some confusion and desperation' is sometimes evident in choices of sources of help, with some 'seemingly inappropriate and unpromising.' And where people make inappropriate choices, they must then look again, or be signposted/ referred on to new advisers, and each time this happens a proportion will give up ('referral fatigue')." 23
There is an evident need to match individual legal problems with the appropriate source of help, and a need to be conscious of the cost implications - for the individual, the legal service provider, the state - of making such matches, if solutions are to be sustainable.

\section{A focus on state funding}

The costs implications of legal solutions has been a consistent feature of the access to justice landscape and a driver of significant changes in state provision or funding of legal services. Sommerlad and Sanderson document the impact of this focus on access to justice in Britain from the mid-1980s through to the implementation of the Legal Aid, Punishment and Sentencing of Offenders Act 2012 (LASPO). Their analysis pinpoints the mid-1980s as a time when:

"the UK could credibly claim to provide access to justice as a result of its extensive network of NFP [not for profit] agencies which, primarily funded by local authority grants, offered welfare advice and a generous legal aid scheme." ${ }^{24}$

There is no romanctising of the period, however, with the authors arguing that there were fundamental problems with legal aid: principally the domination of traditional private practice specialisms, with the consequent criticism that legal aid became "a hostage to law firms' overheads, hourly rates and inefficiencies". ${ }^{25}$ The solution imposed from the mid-1990s was to focus on paying lawyers for the cases they completed rather than the hours they worked, and this model of competitive, contractually based funding for legal services was also applied to funding for voluntary sector organisations. The marketisation and competition that was required for successful tendering was culturally anathema to many third sector organisations, who were also ill-equipped in terms of expertise, infrastructure and resources to manage the bureaucratic impact of contracting. Resolving the problem of having to divert resources from advice and policy work to 'feed the beast' of contracting led to a range of responses: do less complex work, less specialist work, more high output work, lower-quality work, cherrypick cases, or withdraw from whole areas of law. Such 'solutions' also fed into the 'responsibilisation' agenda, promoted by Tory and New Labour governments, that what was required was assistance for citizens to enable them to become responsible for their own solutions:

\footnotetext{
${ }^{19}$ G. McKeever, 'A Ladder of Legal Participation for Tribunal Users’ (2013) Public Law 575-598

${ }^{20}$ These include solicitors, Citizens Advice Bureaux and independent advice agencies, local authorities, the police, health workers, trade unions, professional bodies, employers, insurance companies, politicians, social workers, Jobcentres, financial institutions, court staff, churches, government departments, claims agencies, housing associations, the media, banks, schools and trade associations. 21 P. Pleasence and $N$. Bark, Jobcentres,

${ }^{22}$ P. Pleasence and N.J. Balmer (n 3$)$ p. 4

${ }^{23}$ P. Pleasence and N.J. Balmer (n 3$)$ p. 4

${ }^{24} \mathrm{H}$. Sommerlad and P. Sanderson, 'Social Justice on the Margins: The Future of the Not for Profit Sector as Providers of Legal Advice in England and Wales' (2013) 35(3) Journal of Social Welfare and Family Law 305-327, at p. 308

${ }^{25}$ C. Dyer, 'A purse with strings attached' The Guardian (London, 10 January 1995) 20, cited in H. Sommerlad and P. Sanderson (n 24) p. 308
} 
"the responsibilisation discourse and its narrative of the symbiotic relationship between a disempowering advisor and an (unnecessarily) dependent claimant entailed the construction of the typical client as someone who only needed minimal support and guidance... But few of the [third sector's] clients resembled this model." 26

In particular, individuals with vulnerabilities who present with clusters of legal and non-legal problems will fall outside this 'typical client' model, yet the logical economic response of third sector organisations to the do-more-withless approach was to 'activate' clients to become legally capable - through information services, signposting, and self-help services. While the access to justice research indicates that increasing an individual's legal capability may increase their ability to resolve their legal problems, it is also evident that capacity building will not automatically ensure that capacity is realised or that legal resolutions can be accessed without additional support.

Sectoral capacity - both private and third sector - to respond to the legal needs of vulnerable individuals was further impacted in Britain by the implementation of LASPO. On an operational level, the delivery of access to justice had been built on a complex network of mutually supporting generalist and specialist advice provision, and the impact on this ecosystem post-LASPO has been troubling. ${ }^{27}$ Sommerlad and Sanderson's research highlights the impact of the loss of legal aid funding for advice organisations, and in particular the the loss of specialist advice, with consequential, negative impacts on the capacity of the sector to develop casework and deliver generalist advice. ${ }^{28}$ On an ideological level, the authors reflect the concerns of advice agencies that the general drive towards business models and social enterprise solutions had resulted in "mission drift": agencies were no longer focused on delivering services according to organisational (charitable) values; they had no distinctive identity from private sector providers; and their independence as organisations which challenged the state was lost within their transformation into agents for the state. ${ }^{29}$

In Northern Ireland, similar research has not been conducted with advice organisations to understand their responses to changing funding arrangements, but it is important to note that LASPO - and indeed previous changes to legal aid funding in Britain - does not apply to Northern Ireland, where a different approach has been adopted..$^{30}$ The scope of work covered by civil legal aid has remained greater in Northern Ireland than in Britain. Instead, the Northern Ireland Department of Justice has commissioned two Access to Justice reviews: the first at the outset of the devolution of justice in 2010, designed to embed a first-principles approach to access to justice with the ambition that cost savings would ensue, ${ }^{31}$ and the second commissioned in 2014, in recognition that the necessary level of cost savings had not been reached and intended as a framework within which future funding decisions could be made. ${ }^{32}$ Alongside this, the Department has made a number of reductions in civil legal aid, including taking some areas out of scope, and cutting some funding contracts for specialised areas of work. ${ }^{33}$

\section{Other solutions}

The ability of individuals to access justice is not solely dependent on their financial resources, or the provision of free legal services by the state, although these two issues will have a significant impact on access to justice provision for many individuals. It is also the case that innovative legal solutions need to be delivered to respond more effectively to what citizens need. The search for legal innovations has led to some very successful initiatives - including in the area of online dispute resolution and information provision $^{34}$ - and increased the potential to reconfigure existing, traditional solutions, including through clinical legal education. However, these solutions to how legal services are delivered and funded come with their own limitations and generate considerable concerns about the potential to assist the most vulnerable citizens. While the ideal solution remains elusive, Pleasence and Balmer note that the problem is perennial:

"[T]he legal services market and civil justice system do not ensure fair and equal access to justice, with deficiencies attributable largely to the difficulty of enabling vulnerable populations with limited capability and resources (e.g. those with health problems, low levels of education and/or lower income) to access appropriate help in a complex legal services market in which innovations to broaden service reach have often emanated from outside of the traditional legal professional sphere." 35

In the context of this report, this leaves open the question of whether clinical legal education can function as a justice innovation to enhance fair and equal access to justice. The question demands, first, an understanding of what clinical legal education is and what its potential and limitations might be.

\footnotetext{
${ }^{26} \mathrm{H}$. Sommerlad and P. Sanderson (n 24) p. 311

27 House of Commons Justice Committee, Impact of changes to civil legal aid under the Legal Aid, Sentencing and Punishment of Offenders Act 2012, Eighth Report of Session 2014-15 (2015)

${ }^{28}$ H. Sommerlad and P. Sanderson (n 24) p. 317

${ }^{29}$ H. Sommerlad and P. Sanderson (n 24) p. 316

${ }^{30}$ In short, Northern Ireland has kept more areas within the scope of civil legal aid than Britain. For example, the Access to Justice Act 1999 removed personal injury litigation from civil legal aid in Britain, but this was not replicated in Northern Ireland where it currently remains in scope. The focus for cost savings in Northern Ireland has tended to be on criminal legal aid rather than civil legal aid: see B. Dickson, Law in Northern Ireland (Hart, Oxford, 2013) p. 366.

${ }^{31}$ Department of Justice NI, Access to Justice Review Northern Ireland: The Report (August 2011) https://www.courtsni.gov.uk/en-GB/Publications/Public_Consultation/Documents/Access\%20to\%20Justice\%20 Review\%20Northern\%20Ireland\%20-\%20The\%20Report/Access\%20to\%20Justice\%20Review\%20FINAL\%20REPORT.pdf [accessed 9 October 2015]

32 The Access to Justice Review 2 is expected to be published in Autumn 2015.

33 The Access to Justice Review 2 is expected to be published in Autumn 2015. Department of Justice, Scope of Civil Legal Aid: post consultation report (2015) available at http://www.dojni.gov.uk/index/public-consultations/archive-consultations/post-consultation-report-on-scope-
of-civil-legal-aid.pdf. [accessed 9 October 2015]lt should be noted that the range and extent of areas of law taken out of scope in Northern Ireland is considerably less than the reductions in scope under the LASPO. For example, the Northern Ireland Department of Justice proposes to tighten the eligibility test for private Children Order proceedings rather than remove these cases from scope.

${ }^{34}$ R. Smith and A. Paterson, Face to Face Legal Services and their Alternatives: global lessons from the digital revolution (2014) available at http://www.strath.ac.uk/media/faculties/hass/law/cpls/Face_to_

Face.pdf [accessed 9 October 2015]

${ }^{5}$ P. Pleasence and N. Balmer (n 3), p. 6
} 


\section{Clinical Legal Education}

Clinical legal education (CLE) is the defining term for a form of legal education which exposes students to the practical application of law and puts them in the position of using their legal knowledge to respond to real-life issues. In Giddings' view:

\section{"Clinical Legal Education involves an intensive small group or solo learning experience in which each student takes responsibility for legal or law-related work for a client (whether real or simulated) in collaboration with a supervisor. Structures enable each student to receive feedback on their contributions to take the opportunity to learn from their experiences through reflecting on matters including their interactions with the client, their colleagues and their supervisor as well as the ethical dimensions of the issues raised and the impact of the law and legal processes." 36}

Compared to traditional teaching methods it involves experiential learning, ensuring students are proactive participants in the learning process. ${ }^{37}$ While CLE provides opportunities for knowledge to be applied, it goes further and calls for reflection and self-examination, enabling the student to scrutinise legal and social issues in some depth. Additional to students gaining practical skills, it often increases student motivation and development and sets professional ethics and responsibility within a practical context. The dominant model of CLE is law students working with members of the public to provide access to applied legal knowledge, but may also involve simulations of such problems. CLE can therefore range from law students providing legal advice and advocacy directly to members of the public, to the provision of public legal education on discrete legal issues, to simulated forms of advice and advocacy on which students receive feedback. The focus of this project is on public-facing CLE initiatives, through which law students provide legal advice to members of the public on their legal problems, under the supervision of academics and/or legal practitioners, through in-house clinics, external placements or a combination model that draws together internal and external resources. There are a number of variations on this form of CLE, but overall they tend to be based on a traditional model of individuals going to a legal advice point, engaging in advice seeking that adopts a standard legal interviewing technique which itself tends to rely on a hierarchical, paternalistic approach that remains common in legal practice.

\section{CLE and social justice}

There is a reasonable consensus within the global legal academic community that the pedagogy underpinning CLE is sufficiently strong to justify Law Schools pursuing CLE initiatives. Where consensus is less obvious, however, is on the question of whether CLE should have a social justice mission, or more directly, whether the objective of CLE is to deliver social justice. In part, this tension is explained through an understanding of the origins of CLE, which began in the US in the 1960s and was followed in Australia in the 1970s primarily in response to a lack of accessible legal services for poor. ${ }^{38}$ The initial focus of CLE initiatives was almost exclusively on 'poverty law' - legal problems experienced by low-income individuals who were unable to afford private legal assistance and for whom public legal support was unavailable. From this starting point, CLE was defined as a vehicle for delivering access to justice, and anything that did not adopt this focus was merely an enhanced form of legal training. In the US there was a constitutional imperative to have legal representation for defendants in criminal proceedings who were unable to afford to pay for a lawyer, and there was a corresponding expectation that this need should be met (in part) by US Law Schools. ${ }^{39}$ Major funding investment by the philanthropic Ford Foundation enabled the development of university law clinics throughout Law Schools in the US and supported their focus on social justice. Parallel to this, in Australia, the model of CLE was based in community legal centres and intrinsically linked to poverty law, with the prompt being the lack of alternative services for the poor. CLE became a service that was "grafted" on to existing legal services, and - like the US model - was therefore premised on a service ideal. Part of being a legal professional was seen to be a commitment to public service; CLE could be regarded, therefore, as an important part of legal training since the pro bono ethos was an important aspect of the professionalism of lawyers.

The development of CLE in the UK has not followed this same pattern. The demand for legal support that was met by US and Australian Law Schools from the 1960s was not as evident in the UK, where state provision of support services for low income individuals was more advanced than in the US or Australia. Consequently, there was no event or process comparable to the responsive investment in CLE by the Ford Foundation in America. ${ }^{40}$ While some clinics were established by UK Law Schools in the 1970s the clinical movement did not flourish and its revival has been relatively recent, with clinic development only taking hold from the $1990 \mathrm{~s} .{ }^{41}$ In the UK, the motivation for clinic creation has been focused on 'employability' through the acquisition of practical legal skills, and the conceptual basis of social justice has been superseded by a focus on educational priorities. While social justice can still be delivered, it tends to be as a consequence

\footnotetext{
36 J. Giddings, Promoting Justice through Clinical Legal Education (Justice Press, 2013) at p. 14; R. Lewis, Clinical Legal Education Revisited Cardiff University, Wales, http://orca. cf.ac.uk/27655/1/CLINICED.pdf [accessed 30 September 2015] p. 14 
of a pedagogically focused initiative rather than as its mission. ${ }^{42}$ CLE developments in Europe - described by Wilson as 'the last holdout' - have followed a more ad hoc pattern, where civil law systems and a tradition of theoretical legal teaching have not lent themselves to an easy accommodation of clinical legal practices, creating further departure from the service ideal of US and Australian clinical models. ${ }^{43}$

The tension between pedagogic priorities and a social justice mission remains a feature of the global CLE debate. For some, clinical legal education should be utilised to awaken a sense of social responsibility in students, enhancing their consciousness of the plight of vulnerable groups and developing an awareness of their responsibility to their clients. ${ }^{44}$ Yet for others, clinical legal education should emphasise skills training and professional development over social objectives, such that the mission of clinics within Law Schools should be pedagogically driven, not service driven. ${ }^{45}$ Advocates of CLE therefore oscillate between those advocating for universities to do more to assist vulnerable populations to access the law and those who remain adamant that it is the responsibility of government, not universities, to ensure adequately funded legal services. These tensions are not necessarily irreconcilable: the practical reality is that clinics can provide an opportunity for the most disadvantaged in society to gain access to legal redress, while helping students to understand the position of others in society, increasing student maturity and sense of responsibility as part of their legal skills development, while making a significant contribution to social justice for individual clients. ${ }^{46}$

\section{The marketisation of higher education}

The conceptual basis of a law clinic may help define or determine its approach to service provision, but such developments are as likely to be shaped by cultures of consumerism as by ideologies of social justice. The relationship between universities and students is shaped in part by tuition fees, which weaken the view of education as a social right, and a social good. The recurrent infrastructural funding to enable universities to conduct their core business of teaching and research has long since been privatised in US and Australian universities, and the relatively recent introduction of tuition fees in UK universities, alongside policy driven reductions in state funding, demonstrates a similar shift from public to private responsibility. The consequence is that:

\footnotetext{
"Students have been transformed into consumers, or
}

customers, who choose an educational 'product' according to the reputation of a university rather than according to the excellence of the education."177

The development of CLE therefore sits alongside concerns that higher education institutions are pedagogically constrained by the advancing tide of marketisation, which also puts a social justice mission further out of reach. The model of CLE in the US, for example, appears to have moved away from a core focus on social justice, with the Clinical Legal Education Association - the umbrella organisation for US CLE initiatives - defining its current objectives as being: to foster excellence in teaching and scholarship; to integrate clinical teaching and extend its methods within Law Schools; to prepare law students for excellent and reflective law practice; to advance regulation of legal education to ensure the vitality of clinical education; and finally, to pursue and promote justice and diversity as core values of the legal profession. ${ }^{48}$ The commitment and promotion of justice as an element of legal professionalism is fifth out of five objectives, and it is difficult to anticipate how it could ever surpass the educational focus.

\section{Resourcing CLE}

The further complicating factor for developing CLE is also linked to the issue of resources. Law clinics can be expensive to run due to the small numbers of students that can be accommodated at one time and the need for dedicated and close supervision by Law School staff. ${ }^{49}$ The cuts in state funding for higher education and the consequential impact on institutional resources has led to increased scrutiny of the efficiency of devoting scarce resources to clinic activity. ${ }^{50}$ There are many ways in which clinics contribute to university objectives - providing a service to local communities, delivered in response to local needs, enabling universities to locate themselves within the social and cultural expectations and demands of their surroundings - and the value of such work is not generally quantifiable. Nevertheless, teaching and research constitute the primary means by which public funding is allocated across the higher education sector, and work that does not contribute sufficiently to these objectives, or which draws too heavily on the available resources that these activities generate, may well be vulnerable within a university landscape.

In the UK, research is rated (and consequently remunerated) through a national Research Excellence Framework (REF) which ranks submissions by Law Schools on the basis of quality in research outputs, environment

${ }^{42}$ R. Grimes, 'Learning Law by Doing Law in the UK' (2000) 1 Journal of Clinical Legal Education 54-57; T. Dignan, 'Bridging the Academic/Vocational Divide: the Creation of a Law Clinic in an Academic Law School' (2011) 16 International Journal of Clinical Legal Education 75-84

${ }^{4}$ R.J. Wilson, "Western Europe: Last holdout in the worldwide acceptance of clinical legal education" (2009) 10 (7) German Law Journal 823-846. See also the forthcoming research by C. Bartoli and the European Network for Clinical Legal Education on legal clinics in Europe, which aims to map the range of European clinics and the impact of their services, and a report by L. Donnelly on Clinical Legal Education in Ireland: Progress and Potential that has been commissioned by the Free Legal Advice Centre and the Public Interest Law Alliance in Ireland and will be launched in October 2015.

44 S. Wizner, 'Beyond Skills Training' (2001) 7 Clinical Law Review 327-340, at p. 329

45 TS. Wizner (n 44) p. 332

${ }_{46}$ R. Lewis (n 36) p. 7-11

4 M. Thornton, Privatising the Public University: The Case of Law (Routledge, 2012) p.12-13

${ }^{48}$ Clinical Legal Education Association, Mission (2011)<http://www.cleaweb.org/mission> [accessed 9 October 2015]

49 L. Bleasdale-Hill and P. Wragg, Models of Clinic and Their Value to Students, Universities and the Community in the post-2012 Fees Era (2013) 19 International Journal of Clinical Legal Education 257-269

p. 257; M. Thornton (n 47) p. 83

so L. Bleasdale-Hill and P. Wragg (n 49) p. 257-258 
and impact. The law subject panel that conducted the quality rating for the most recent research exercise in the UK - the REF 2014 - welcomed the inclusion of research on legal education but noted its concern that the "methodological rigour and significance exhibited by some of these outputs was uneven". ${ }^{51}$ Such variations or gaps in the quality of legal education research has the potential to stymie research in this area if universities are not convinced that the quality threshold can be met. However, there remains potential to develop rigorous, high quality research based on clinical, empirical work. One clear option is to use the insights gained from a frontline understanding of how the legal system is working: to reflect on and analyse the manifestations and implications of the legal problems faced by clinic clients and use this to develop access to justice focused research agendas. Clinics can provide a microcosm of the legal advice landscape and they offer considerable potential to identify systematic barriers to justice for clients, providing rich data on which research can build and contribute to policy agendas, to meet both quality and impact targets for research..$^{52}$ If this vein of research was to be exploited successfully the future for law clinics as integral parts of a Law School might also improve.

The pedagogic justification for clinical legal education has already been noted, but the advantages still have to be balanced against the resources required to sustain high quality teaching. Marson et al develop the argument that Law Schools have traditionally suffered from underfunding compared to other subject areas. ${ }^{53}$ They analyse the funding formula which supports university teaching, pointing to clinical subjects such as medicine and dentistry receiving the highest funding per student, followed by laboratory-based subjects banded just below this, with the lowest funding band allocated to classroombased subjects including law, as well as humanities, business and social science. Clinical legal education, it is argued, demonstrates the need to re-band law to reflect the laboratory-type teaching that is employed, with the corresponding need to increase the level of resources to match. The merits of this argument, however, have not yet been accepted by funding bodies and so the balance on the basis of existing resources will need to be maintained. Further developments in assessing teaching quality are anticipated, with the potential for a 'Teaching Excellence Framework', conceptually based on the REF, currently being considered by the UK government. ${ }^{54}$ While it remains unclear what this form of teaching assessment would focus on, the pedagogic strengths of clinical legal education could make an important contribution to demonstrating high quality, student-focused and professionally relevant teaching and enable further stability for the future of university law clinics.

\section{Conclusion}

The context in which UK university law clinics operate is therefore positioned between a demonstrable need for additional or alternative access to justice for those unable to secure legal support for themselves and a need for universities to deliver an educational offering that enhances their reputation and is respectful of the impact of reduced state investment in higher education. CLE therefore encompasses multiple ambitions: delivering access to justice, providing high quality teaching and research, and adding value to the student learning experience such that the additional resources demanded by CLE can be justified. These ambitions may be mutually supportive, but there are inevitable conflicts that can arise in attempting to fulfil all of them, with no clear framework to establish what precedence one objective should be given over the others. The priorities are most likely to be determined on an institution by institution basis, but where the focus is on institutional excellence in core business areas then access to justice is least likely to succeed as the priority objective. The ability of publicly funded legal services to meet the demand for legal need is already compromised and further funding reductions look likely to grow the gap between demand and supply. The potential for university law clinics to step into this gap, or to reduce it, may give universities cause to consider what they can realistically provide and what their role in delivering access to justice might look like, within the confines of their own institutional objectives. What this project seeks to understand is how university law clinics in the UK are responding to this prospect: how do they see their role, both in principle and in practice, and what contribution are Law Schools able to make to the ecosystem of legal advice? Part two now offers an analysis of these questions through the survey evidence provided by UK university law clinics.

\footnotetext{
${ }^{51}$ Research Excellence Framework 2014, Overview Report by Main Panel C and Sub-Panels 16 to 26 (January 2015)http://www.ref.ac.uk/media/ref/content/expanel/member/ Main\%20Panel\%20C\%20overview\%20report.pdf [accessed 9 October 2015] p. 71

${ }^{52}$ See G. McKeever, Clinical Legal Education as an Access to Justice Innovation (OxHRH Blog, 12 September 2014) http://ohrh.law.ox.ac.uk/?p=13598 [accessed 9 October 2015]

$53 \mathrm{~J}$ Marson, A. Wilson and M. Van Hoorebeek, "The necessity of clinical legal education in university Law Schools: a UK perspective" (2005) 7 International Journal of Clinical Legal Education 29-43

${ }^{54}$ HEFCE, 'New approach to ensure high-quality learning and teaching in universities and colleges', Press release 29 June 2015, available at http://www.hefce.ac.uk/news/ newsarchive/2015/Name,104412,en.html [accessed 9 October 2015]
} 
Part 2 - CLE survey analysis and findings 


\section{Part 2 - CLE survey analysis and findings}

\section{Methodology}

In order to understand the role of university law clinics within the UK justice landscape a survey methodology was employed, designed to probe both the nature of legal service provision offered through clinics and the extent to which clinics focus on delivering access to justice, with survey questions developed from themes that emerged in the access to justice and clinical legal education literature. Following identification of the necessary content, the survey was developed through a generalised and user-friendly web-based programme which enables the creation of survey instruments, the distribution of surveys, data storage and analysis. The survey was then made accessible through a direct and confidential web link to the web-based survey platform.

The survey was comprised of 63 component questions with varied question types, including multiple choice and single choice questions, rating scales and comment areas to enable participants to elaborate on previous responses. The questions were arranged in a respondent-friendly design to ensure the survey was understood easily by users. This included an expanded definition of terms for participants where necessary, for example Question 15 asks, In order to enable the clinic to deliver its services, does the clinic have formal collaborative arrangements? This was clarified for users with the addition of a caveat explaining for the purpose of this survey, collaboration is defined as clinics working with other individuals/ organisations on a client's case. In addition the survey was designed to be easily navigated, permitting respondents to return to previous questions if necessary, and the design utilised embedded skip logic to ensure participants could bypass questions they were not required to answer. The number of responses varied with each question, with some questions getting full responses and some not answered by all clinics. The survey was designed to take approximately 15 minutes to complete.

Initial distribution of the survey was facilitated through an email request from the UK Clinical Legal Education Organisation - an informal organisation of academics with an interest in clinical legal education - to a mailing list of its members, and broadcast through social media, namely Twitter and Facebook. While this enabled contact with a wide range of academics with a self-identified interest in clinical legal education, there was a need to ensure a systematic approach to enable the survey to be distributed to all university law clinics in the UK. The project therefore constructed a list of university law clinics, identifying law clinic activity through the websites of all UK universities - the list of which was accessed via the Universities UK website - cross checking with clinic-relevant terms, which included 'law clinic', 'clinical legal education', 'pro bono', and 'law'. This ensured the identification of the target population, namely Law
Schools with clinics. Contact details of universities with identified law clinics were documented, as were the email addresses of Heads of Schools, and surveys were distributed from 15 June 2015. This was also matched against the UK clinic database held by LawWorks - a national charity working with solicitors in Britain to support pro-bono activities across the profession - to ensure no university clinics were missed. The LawWorks database lists 170+ law clinics but this includes clinics not connected to UK Law Schools and only those Law Schools that have registered with LawWorks are registered on its database. The survey link was sent via directed emails to named contacts and/or Heads of Schools, with followup emails to prompt responses. The survey response deadline, originally set for 20 July 2015, was extended to 31 July 2015 to capture additional responses.

We identified that there were 102 UK Law Schools, 64 of which had clinic-relevant activities. Of these, two responded to rule themselves out of the survey; with one still at the set-up stage that did not expect the clinic to start until late 2015/16 and the other offering an alternative clinic model as a company limited by guarantee which was run by students rather than being conducted by the university. Of the remaining 62, 33 respondents entered the survey and 32 survey responses were completed successfully, giving a survey completion rate of $97 \%$. One survey was not completed. Our survey response rate, therefore, was $52 \%$.

\section{Clinic profiles}

The responses to the survey were from clinics which were established between 1990 and 2015, with one clinic having initially been opened from 1973 to 1977 , and reopened again in 1991. Only 5 were set up in the 1990s, with a further 11 established between 2000 2010, and the remaining 16 established between 2011 to 2015, illustrating an acceleration of clinic creation in the last 5 years among our survey respondents. It may be that the newer clinics were more likely to respond to the survey, and that the inclusion of clinics which did not respond would change this profile, but our findings correspond with the documented trajectory of clinical legal education, with the UK clinic movement really only beginning to take shape in the 1990s, and with the survey evidence of the Law Works Law School and Pro Bono Clinic Report 2014 which shows a historically increasing amount of pro bono and clinical activity. ${ }^{55}$

University law clinics are being run with small numbers of academic staff, with the exception of one clinic which has 22 staff and which services an integrated degree combining the undergraduate programme with a professional legal qualification. On average the respondent clinics have two academic staff, but there are variations within this as well - some are full time, some are part time, some just provide oversight, some operate on an ad hoc basis. Most clinics have some administrative/clerical support but this also varies: six clinics have no support; two have staff on low part-time hours; two clinics had three/ 
four administrative staff; and one clinic used students as the clerical/administrative support. In addition to internal staff, clinics rely heavily on external supervisors - at the high end ranging from 20 to 150 - with a variety of other staff brought in including PhD students, interns, teaching assistants and specialist academic staff. The survey did not ask if these additional staff were recruited specifically to the clinic, so they may be staff specifically appointed to the clinic or it may be that clinics are making the most of the staff/student profile within their Law Schools to take advantage of the professional experience or qualifications of existing academic staff.

In relation to clinic funding all respondents stated that they were funded by university funds, with a number of clinics also receiving additional sources of funding. Eight (26\%) stated that they received funding from private donors; five (16\%) received funds from charitable trusts; and one (3\%) received funding through central government. Additionally, clinics stated that they generated additional sources of income through practitioner contributions, fundraising and charity events. The findings of the Law Works 2014 survey indicates that the trend for Law Schools to receive external funding has been in decline, with significantly fewer Law Schools receiving external funding year on year. ${ }^{56}$

The numbers of students participating at undergraduate level averages at 59 per year, but there is an outlier figure of 360-400 undergraduate students per year at one clinic which pushes the average to 70 . Seven clinics have fewer than ten undergraduate students, including three clinics which take only postgraduate students. 20 clinics have postgraduate students (compared to 29 clinics with undergraduate students) but there is a wide variation in the numbers of postgraduate students who participate in university law clinics. The average (mean) number of postgraduate students is 26 , with two being the lowest and 150 being the highest number of students, and $55 \%$ of the 20 postgraduate clinics taking ten or fewer postgraduate students. Overall, therefore, the findings indicate that there is no general pattern or standard size of university law clinics, either in terms of staff or student profiles or numbers, suggesting that clinics are bespoke creations by Law Schools to meet their individual and varying needs. The advantage here - particularly from a university perspective - is that the clinic model is not artificially confined or restrained, but the disadvantage from a wider access to justice perspective is that clinics do not offer a standard service or package that can be used as an off-the shelf replacement or automatic supplement to existing advice provision.

The survey provides evidence of the volume of clinic cases and of clinic interactions with other advice providers, but it does not map or correlate the provision of advice through law clinics with the range of advice providers in the locality of the clinic. If this gap was addressed - for example, by including university law clinics within a mapping project that could identify the range of service provision within different geographical areas - this could create a better sense of the significance of clinic services vis a vis other advice provision, and develop a more comprehensive understanding of the interdependent relationship between clinics and other advice services.

\section{Areas of law covered}

The most common area of law that clinics provide advice in is housing law, which is covered by 27 out of 32 of the respondent clinics (84\%). Commercial law, (including company law, contract and intellectual property) follows this, with 24 clinics offering support in this area; and 24 covering consumer law. Family law is covered by 21 clinics; employment law by 16 clinics; health and social care covered by 12; and immigration (including statelessness), criminal law and education are each covered by nine clinics. Social security law is covered by seven clinics; five cover asylum; three cover human trafficking; property; probate and wills. There are a range of 'other' areas of law covered by clinics, including: criminal injuries compensation, property law, neighbour disputes, inquests, environmental law, debt, planning, human rights and data protection, with one respondent clinic covering "all areas" of law.

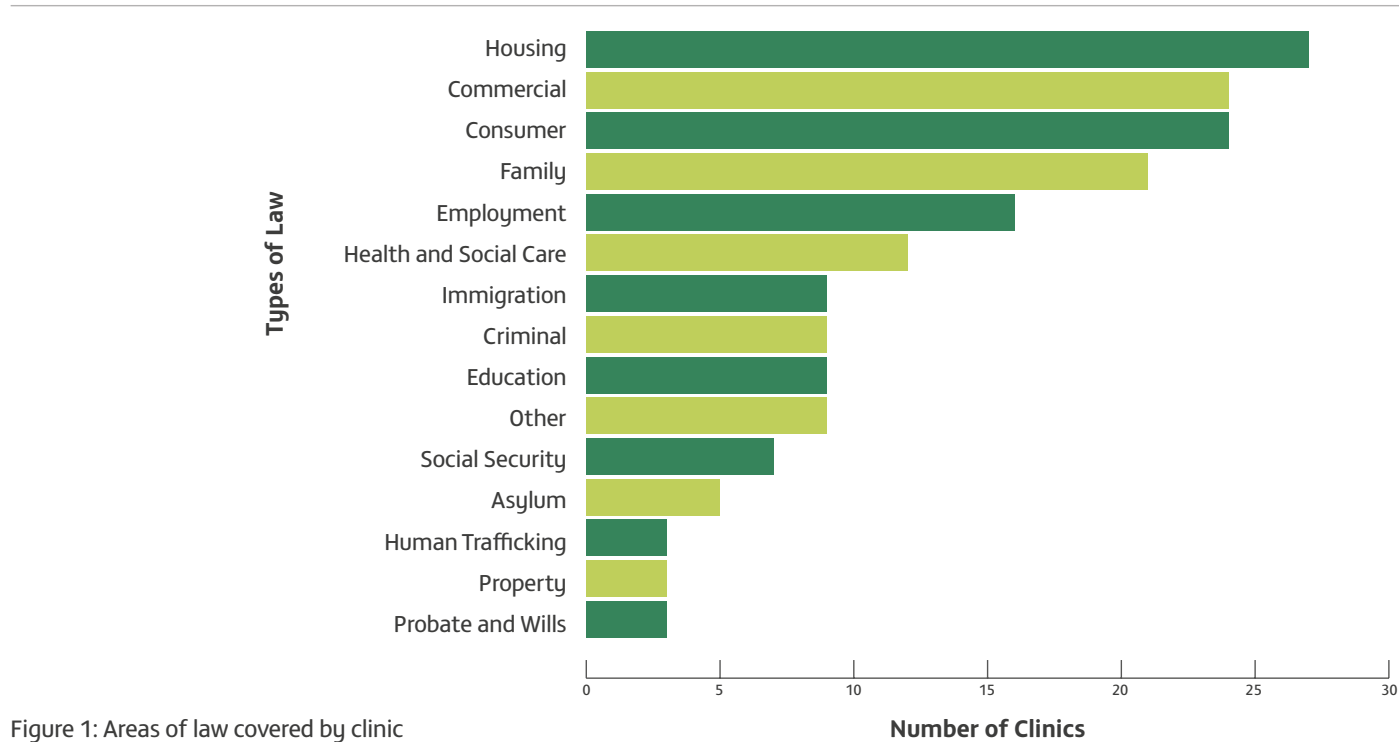


Clearly the range of what clinics can cover is diverse, suggesting on the one hand that clinics could be set up to cover almost any area of law, but the survey also identifies a clear set of limitations on clinics, specifically in relation to the capacity and expertise of academic staff in being able to supervise casework in particular areas. The findings indicate that the theoretical possibility of all clinics being able to cover any area should be tempered by the practical reality that Law School clinics, in the main, are not extensively resourced and limitations on what can be covered are more likely to be the norm. It may also be worth considering whether the clinic specialisms reflect the consumerist sentiment identified in the literature that sees the employability agenda of universities led by student and employer expectations that will include exposure (through clinics, as well as other parts of the curriculum) to areas of legal practice in most demand by prospective legal employers.

\section{Clinic caseloads}

Clinics carried an average (mean) caseload of 104 cases per year, although the median figure is 70 , and the mode is 100 . As figure 1 shows, ten of the clinics took over 100 cases per year with 21 clinics taking 100 or fewer cases. $35 \%$ of respondents stated that the number of clinic cases had remained constant over the last three years, but $61 \%$ said that their case numbers had increased, with one respondent clinic (representing 3\%) stating that their case numbers had decreased in the last three years.

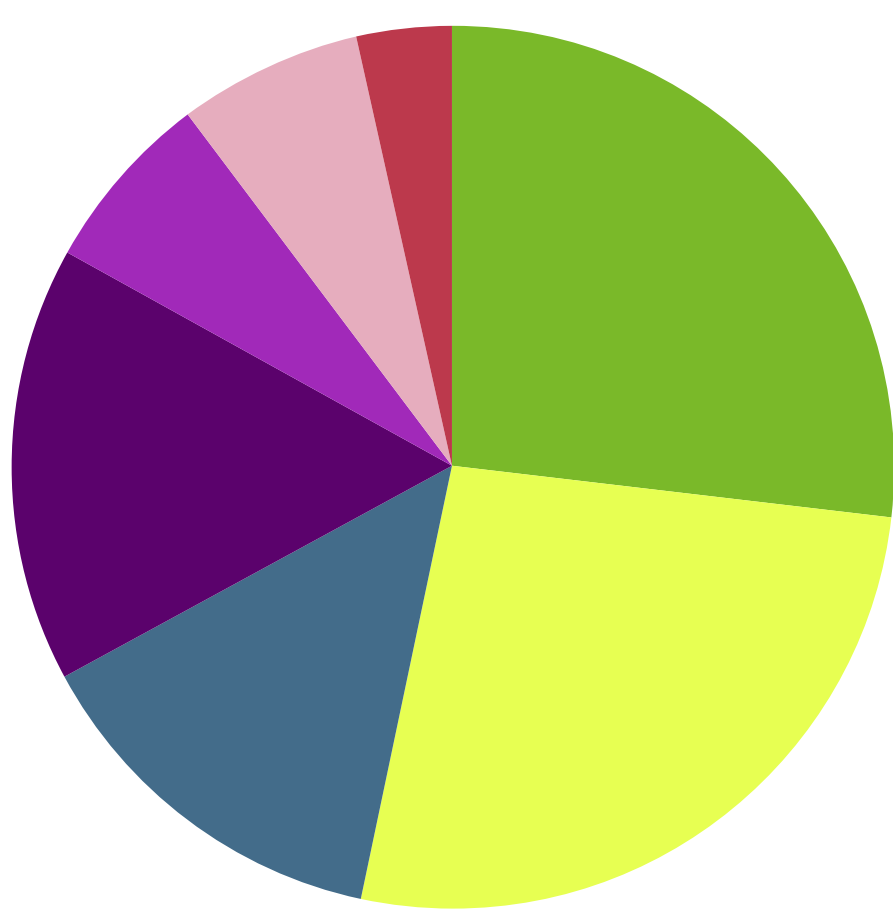

5-40 cases per year

50-90 cases per year

100 cases per year

120-200 cases per year

240-380 cases per year

400-500 cases per year

$500+$ cases per year

Figure 2: Approximate number of cases clinics handle per year

Changes in clinic caseloads were seen to be related to three factors. The most frequently cited factor (listed in 10 out of 20 responses) was changes in clinic capacity and staffing (including reduced staffing which was cited by one clinic as a reason for the reduction in annual clinic caseload). An increase in legal need with a corresponding reduction in alternative sources of legal help was seen as the next most significant reason for clinic caseloads increasing from previous years, with nine responses citing this as a reason. The third factor, cited as relevant by three respondents, was an increase in the visibility of clinic services (seen as resulting from external collaborations and increased advertising by clinics).

26 out of 31 respondents ( $84 \%$ ) stated that, over the last 3 years, there had been an increase in the volume of enquiries and referrals to their clinics, with the remaining 5 respondents noting that this volume had remained relatively constant. The reasons attributed to the increase in enquiries and referrals mirrored those given for the changing clinic caseloads: clinic capacity and staffing; increased legal need; and increased visibility of the clinic. The increased demand for legal support was cited as a reason in nine of the responses ( $29 \%$ ), and, within this, respondents cited the reductions in legal aid and an increase in referrals from independent advice organisations and social services as factors driving the increase.

The findings show that external factors driving clinic demand and caseload are balanced against the internal resource constraints faced by clinics. Pleasence and Balmer's research highlights the continuing impact of the 2008 recession leading to a higher likelihood of individuals experiencing justiciable problems, with the entrenched economic downturn having a significantly negative effect on personal finances, employment, job stability, 
welfare benefits, housing, marital/personal relationships and mental health. ${ }^{57}$ The changes to the funding of public legal services have inevitably contributed to a rationalisation of free legal advice but the driver for clinics to increase their caseloads is more likely to be because clinics have additional staffing than because there is an increased legal need. The survey responses also reveal that $61 \%$ of clinics saw an increase in their annual caseload, but $84 \%$ saw an increase in demand, illustrating some disparity between demand and supply.

\section{Connections with other service providers}

22 respondents identified the type of services their clinic provided. Of these, 13 provided an advice-only service, with one clinic identifying that the 'advice' was by way of outlining legal options rather than "firm advice" (clinic number 20). Nine clinics provided advice and representation, although the latter group includes two clinics that stated they "sometimes" represented "if necessary" (clinic numbers 16 and 21). Clearly not all clients will require representation and, for some, adviceonly may be sufficient to deal with their legal problem. However, the limitation of service raises questions about where this leaves clients on their advice seeking journey - and specifically whether it creates a fragmented or incomplete journey. It is likely that not all clinic clients would require representation, but equally likely that some will require this form of support.

The danger inherent in only being able to deliver a partial service is that the client's path to justice runs out, and so the survey sought to establish whether clinics interact with other providers of legal support to help clients continue with their journey. Clinics were asked about whether they had collaborative and referral arrangements with other providers, and whether they signposted clients to other relevant services. Collaboration was defined by the survey as working with other individuals/ organisations on a client's case. 24 of the 32 clinics (75\%) stated that they had formal collaborative arrangements, with the majority of these being with solicitors (50\%), independent advice agencies (38\%), and barristers (28\%). Others had formal collaborations with in-house lawyers in external organisations, legal charities (such as the Free Representation Unit and the Personal Support Unit) and the civil courts. Eight (25\%) of the 32 clinics surveyed stated that they did not have any formal collaborative arrangements, and five clinics (16\%) stated that they had no informal collaborative arrangements, with the remaining 26 clinics ( $81 \%$ ) having some informal collaboration arrangements with independent advice agencies, solicitors, barristers, advocates, social services and in-house lawyers for external organisations. The survey did not establish whether the clinic collaborators were able to continue with clinic cases when clinics reached the limit of their own service provision, and so it is not possible to conclude that the collaborations advanced the client's journey. However, clinics were asked what value the collaborative arrangements brought to the clinic, and what reciprocal value clinics brought to their collaborators. The main value clinics saw in collaborations were in relation to supervision, expertise, capacity and support, with two clinics (out of 27) specifically identifying the follow-up work that could be done by collaborative partners as a benefit to the clinic. The value that clinics felt they brought to their collaborative partners appeared to differ depending on whether the collaborative partner was a private firm or a public or charitable organisation. The advantages of collaboration for private corporations was seen predominantly to be a contribution to their corporate social responsibilities and associated pro bono activities. Where collaborations were with charitable or publicly funded organisations, the collaboration was seen as a means of enabling an increase in that organisation's services, and alleviating some of the pressure resulting from reductions in organisational funding.

In relation to the perceived value of collaborations with charitable or publicly funded organisations, this may invert the original question raised by the limitation of clinic services, so that rather than seeing clinics as offering only a fragmented or incomplete journey for clients, the clinics themselves can provide the next step for clients on the path to justice. To continue the analogy, the road may still run out, but it may have run out sooner if the clinic was not there.

Referral arrangements were defined for the purpose of the survey as handing a client's file on to another organisation or individual who has agreed to help the client. The clinics surveyed were split quite evenly between those that had some and those that had no onward referral arrangements with other organisations or professionals. $47 \%$ (15 out of 32 ) of the clinics surveyed have either informal or a mixture of formal and informal referral arrangements, and 53\% (17 out of 32 ) have no referral arrangements with other support providers.

Referrals were made to a wide range of people, the range reflecting the same range of advice and support providers that are ordinarily accessed by advice seekers (Figure 3). ${ }^{58}$ Predominant among these were solicitors used by 13 out of 15 clinics - followed by independent advice agencies - used by 12 out of 15 clinics - and then barristers - used by 9 out of 15 clinics. Professional bodies, local authorities and politicians were the next most common referral partners, and the 'others' who were specified were legal charities and pro bono organisations (such as the Free Representation Unit) and nondepartmental public bodies. ${ }^{59}$

\footnotetext{
${ }^{57}$ P. Pleasence and N.J. Balmer, ‘The Audacity of Justice: Recession, Redundancy, Rights and Legal Aid' (2010) 9(4) Social Policy and Society 475-488; P. Pleasence and N.J. Balmer, 'On the Rocks: recession-related life problems and relationship stability' (2012) 24 Child \& Family Law Quarterly; P. Pleasence, N.J. Balmer and R. Sandefur, Paths to Justice: A Past, Present and Future Roadmap (UCL Centre for Empirical Legal Studies, 2013)।

${ }_{58}^{8}$ See Part 1, p. 8, $n 20$ for the range of advisers sought by individuals

${ }^{59}$ The Law Works Law School survey ( $\mathrm{n} 41$ ) also identified a high volume of Law Schools working with legal practitioners on their clinical and pro bono activities: p. 29
} 


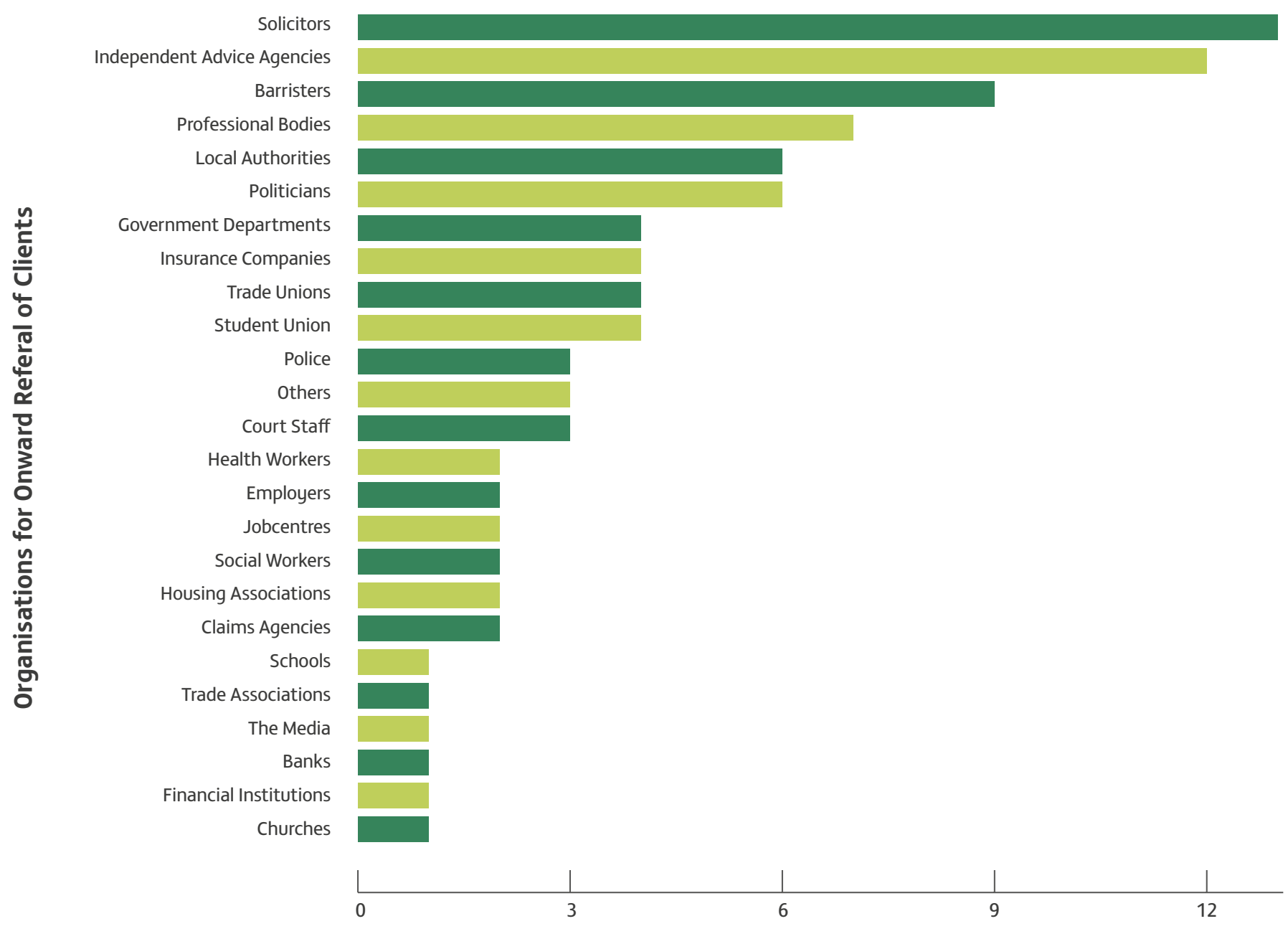

Number of Clinics

Figure 3: External bodies who take case referrals from clinics

Clinics identified mutual benefits from referral arrangements, recognising in particular the value to clients of a joined up service to make their advice journey more complete. In practical terms, clinics saw referral arrangements as enabling them to manage the clinic's casework capacity, and to build capacity for external partners. In terms of skills and expertise, clinics identified the benefit to referral partners of clinics doing case preparation work, with the referral organisation doing the specialist, skilled work beyond the clinic's competence.

The survey also asked clinics whether they signposted clients to other services, with signposting defined as identifying other potential organisations or individuals who may be able to help the client. 31 out of 32 clinics stated that they would signpost clients, once again indicating that the client's journey may not always complete with the clinic. The value of effective signposting is that the most relevant assistance is identified for clients, and the practical barrier faced by individuals in knowing where to go for advice is overcome. The difficulties, as evidenced through the access to justice literature, is that clients become too fatigued to follow through, that the signposting is not effective in identifying the best source of assistance, and that the identification of a relevant source of advice does not always equate to that advice being available. While a 'warm handover' may be more effective in avoiding client fatigue, this may not always be possible, particularly when the need for signposting is because the client enquiry does not match the clinic's area of work. These are not problems peculiar to law clinics, but they do point to clinic involvement in more fundamental issues about the need to match clients to the right service providers and the need to develop and protect effective relationships among different legal service providers.

\section{Client profiles}

The survey sought to establish whether clinics collected data on clients, to ascertain how relevant the profile of clinic clients was to the work that clinics were doing, or planning to do. As Figure 4 shows, three out of 32 respondents ( $9 \%$ indicated that they did not collect client data. Of the remaining 29 (91\%), data was collected across a range of indicators, although some respondents noted that the data collection was matched to the type of case so that only what was "necessary" was collected. For example, data on nationality and ethnicity might be collected in relation to asylum or immigration cases, but "is not routinely collected" for other types of cases (clinic number 22). 


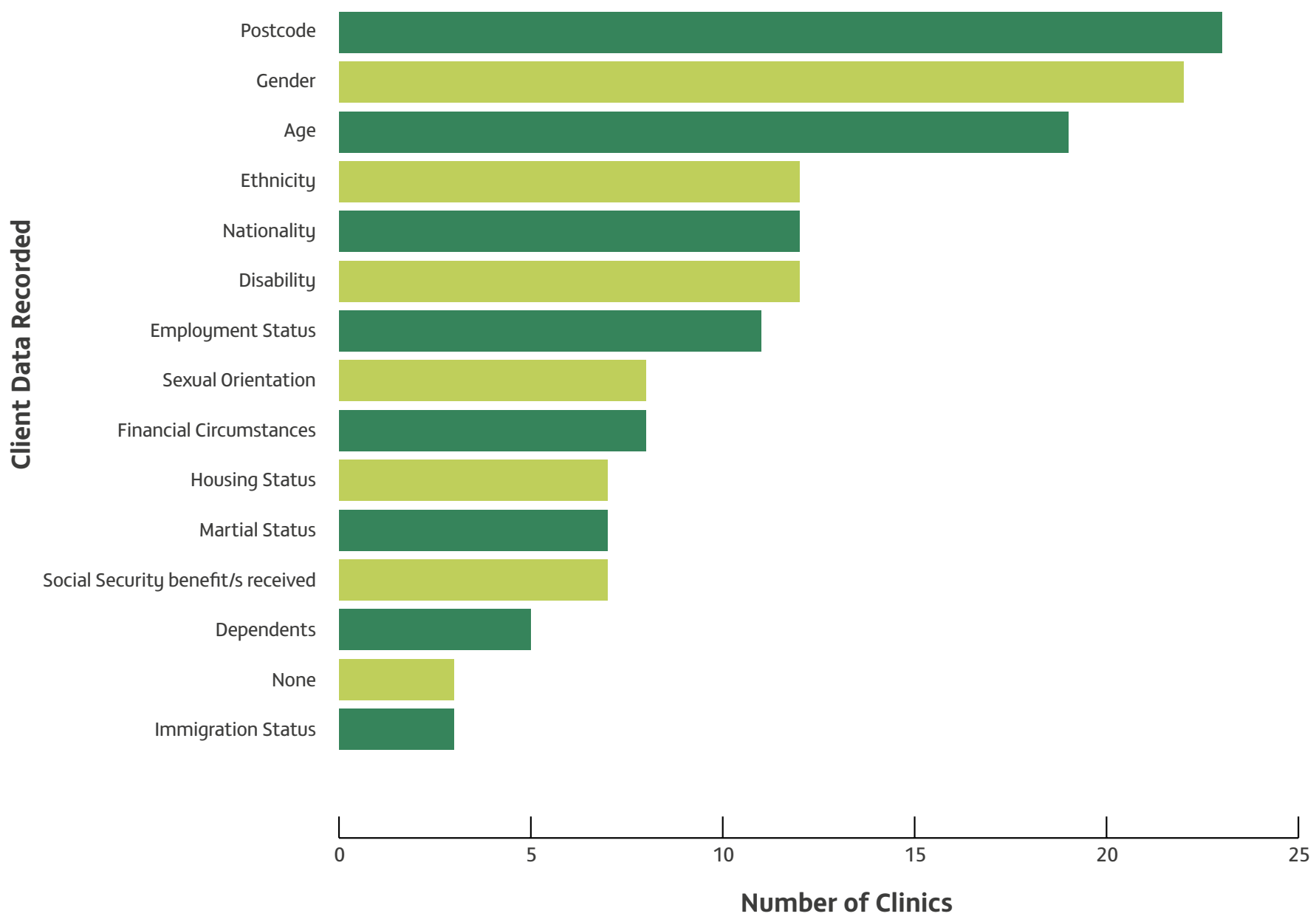

Figure 4: Types of client data recorded by clinics

Clinics recorded data for two main purposes: reporting (to funders; for equality monitoring; to LawWorks surveys) and to identify legal need. Ten clinics identified reporting requirements as a reason for data recording, and ten cited legal need as their reason for data recording, with legal need being interpreted as a mixture of information deemed relevant to the nature of the client's case and a means of assessing the nature of legal need in the clinic's catchment area. Related to this, two additional clinics identified client data as necessary to determine the client's financial position, with one using this to determine if clients could afford alternative support and one to determine client eligibility for legal aid. Two clinics said that the purpose of recording client data was to target future clients.

In describing client profiles in narrative terms, 12 out of 25 respondents specifically highlighted issues around the financial status of clients, stating that clients were typically low waged or on a low income, unemployed, in receipt of social security benefits, and unable to afford to pay for legal advice. Yet, as figure 4 above shows, only a quarter of clinics said they collected specific data on financial circumstances: eight out of 32 respondents (25\%) indicated that they collected data under this heading, although it is also possible that other data indicators may act as proxies for this information, including employment status and receipt of social security benefits. Of those clinics that did collect data on client financial circumstances, the most common method of collecting data was for clients to provide an informal declaration that they were unable to pay for legal support, with two clinics establishing proof of income through bank or pay statements. Housing status, employment status and receipt of defined social security benefits were each used by one clinic to determine client financial status, and the survey findings indicate that clinics would seek to rely on "client honesty" as a way to indicate financial status, suggesting that full and formal financial background checks are not part of the clinic ethos.

\section{Case selection criteria}

Related to this finding is the fact that only a quarter of clinics limit their services based on financial need: eight out of 32 clinics ( $25 \%$ ) impose this limitation. For the remaining 24 clinics (75\%), the financial need of clients is not the determining factor in accepting their case. Eight clinics specifically justified not imposing this limitation on their service as being "not relevant" to what the clinic does, with a further five citing the need for cases to have an educational value as being more important than clients being of limited means. Four clinics stated that they did not record financial 
data on clients as it was too difficult, and two clinics worked with external partners on cases, either as the inward referral point to the clinic or onward referral to the external partner, so case eligibility was based on factors relevant to those external partners. For the quarter of clinics that said they limit services based on financial need, one clinic caveated their answer, stating that:

\section{"if a case of particular educational benefit is brought to the clinic we may take it on (if no solicitor engaged) in certain circumstances even if the client is not of limited means if they would NOT otherwise be seeking professional legal advice." (clinic number 3 )}

The indication here is that the educational objectives of the clinic remain an important - and potentially overriding - consideration, even where case selection policy is based on financial need. Three clinics stated that the service limitation based on financial need was imposed to ensure that the clinic could meet its objective of providing legal help to those without the means to secure this from elsewhere, and three clinics identified using financial eligibility criteria as a defence to any perception that the clinic was competing with other legal practitioners.

It is clear that clinics do have some service limitations and that these limitations operate even where there is no formal restriction stipulated through case selection criteria. Eight out of 32 clinics (25\%) stated that they do not have case selection criteria. Clinics established for 18 months or less - those who saw themselves as "too new, too few cases" (clinic number 18) - felt that the limitation they faced in providing a full service was that there were not enough cases to service. However, an analysis of the reasons given for not having case selection criteria indicates that clinics do, in practice, limit the cases that come to clinic. For example, one clinic defined itself as having an open-door advice service, but this was limited to those areas of law covered by the clinic, or where there was no conflict of interest, or the timeframe for advice could be met (clinic number 5), while another clinic determined eligibility through a practice of 'first come, first served' (clinic number 32).

24 clinics (75\%) identified the specific elements within their case selection criteria, with the predominant factors being complexity (cited in 17 responses) and area of law (cited in 16 responses). Nine clinics used a determination of whether there were alternative sources of legal help available in their case selection criteria, with three responses linking this very clearly to an access to justice focus. Five clinics cited client income as a criterion and five considered whether the client's need for advice was urgent or could be accommodated within a longer, student-focused timetable. The educational benefit of the case was only listed as a selection criterion by four clinics. Two clinics cited capacity as part of their criteria; one cited conflict of interest (with the University and with other clinic cases). Only one cited the strength of the case as forming part of the selection criteria. The reasons for choosing these criteria were largely practical: 10 clinics identified the need to ensure that the clinic had capacity for the casework, including their ability to manage cases and match cases to student availability, and five clinics identified the need to match staff expertise to clinic cases, with three citing criteria deriving from the responsibility to ensure client needs could be met. The need to meet educational objectives was also significant, with eight clinics noting that case selection criteria was based on this, and one clinic stating that the exclusion of complex, potentially contentious and emotionally charged cases was to "protect students from being unduly affected by [a] sense of responsibility for the lives of children" (clinic number 27). Two clinics specifically identified their choice of case selection criteria in relation to an access to justice objective.

The reasons for most clinics accepting, or rejecting, cases, is therefore not one that privileges the client's need for access to justice over all other factors. The practical limitations faced by clinics are the biggest driver of case selection, and this includes a strategic focus on what is required to meet the educational needs of the clinic students. The access to justice focus is not necessarily at odds with the educational focus, but there is a consistency in clinic responses that education is the driving force - both in terms of educationally valuable cases and of the capacity of staff and students to manage the cases. There is a further point to be observed from this analysis and that is the relative luxury for law clinics in not having to use market-driven principles of value-for-money in determining whether to accept or reject cases, and which Sommerlad and Sanderson's research identifies as causing 'mission creep' within advice sector agencies in Britain. ${ }^{60}$ This may offer some potential for optimism that the social justice mission of clinics (where this exists) is not under the same threat as may be the case for other advice organisations.

\section{Paths to the clinic}

The majority of clinics accepted clients who self-referred to the clinic, with 31 out of 32 clinics accepting clients on this basis. 27 clinics (84\%) accepted clients who were referred to the clinic by an external body, with only five clinics (16\%) not taking clients on this basis.

Where clients were referred to the clinic, the vast majority ( $93 \%$, or 25 out of 27 responses) were referred by an independent advice agency, and over half ( $52 \%$, or 14 out of 27) were referred by court staff, suggesting that clinics are visible to those dealing with frontline queries. The next most common sources of referral were solicitors (48\%), students unions (48\%) and local authorities (44\%). Eight clinics (30\%) took referrals from housing associations, trade unions and politicians; six (22\%) took referrals from barristers and social workers; five (19\%) from health workers and the media. Three clinics had referrals from churches and the police; two from schools and jobcentres; one clinic had a referral from employers; one from a government department; one from a non-departmental public body; and one from a trade association (Figure 5). 


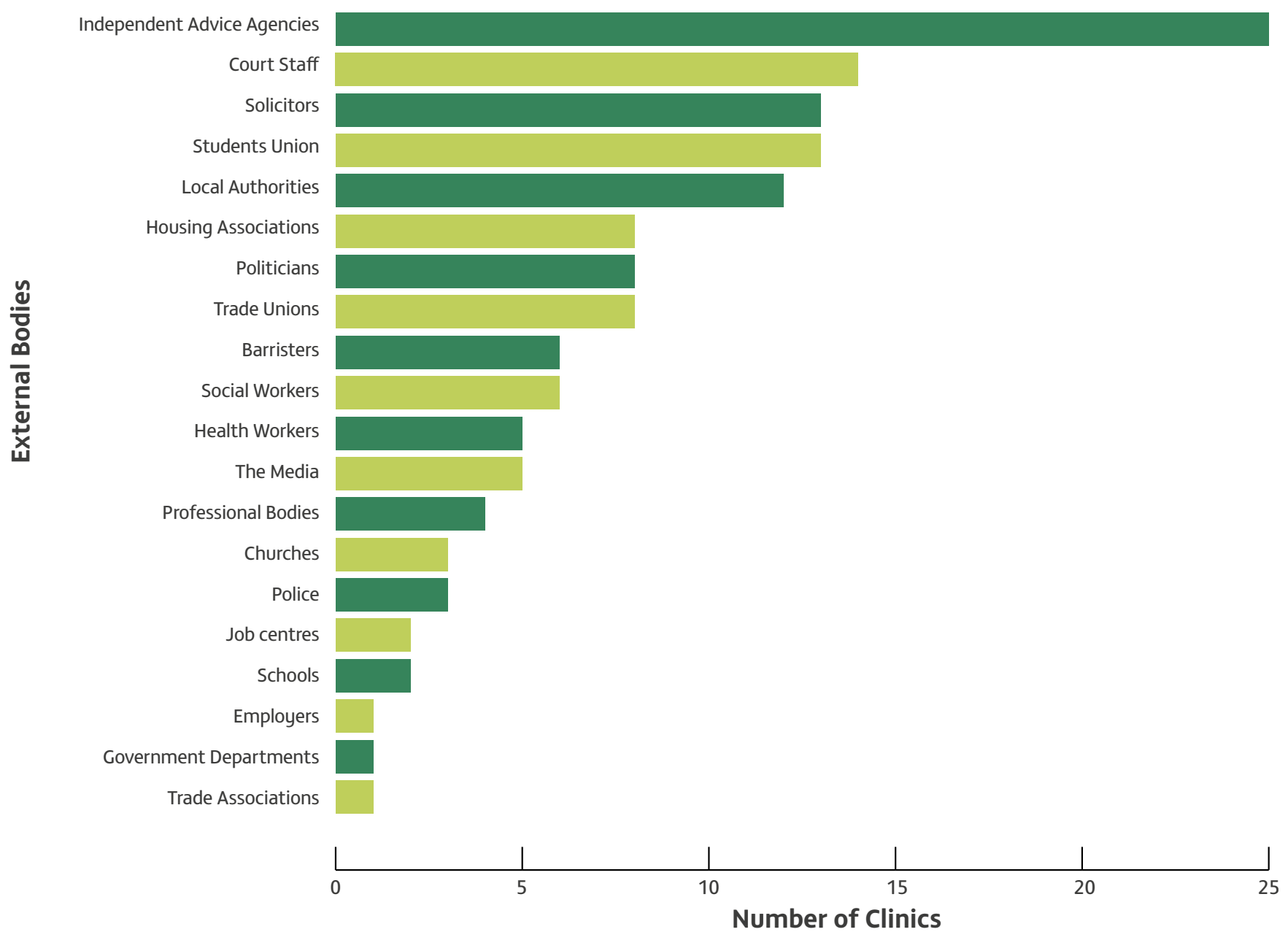

Figure 5: External bodies who refer clients to university law clinics

The range of individuals and organisations from which referrals arise is probably predictable, since it reflects the range of bodies to whom individuals bring legal problems, even when the problems are not categorised or understood by those individuals as legal. What is interesting, however, is that the data demonstrates the connections between these bodies and university law clinics. In addition, the fact that so many of the respondent clinics also have clients who self-refer suggests that clinics are not just visible to front-line advisers but may be directly visible to members of the public who are seeking advice. The data does not make any claims as to the scale of visibility; it only tells us where clinic visibility is greatest among the different connecting advice service providers, and to local clients, but it does evidence that university law clinics have a place alongside other advice providers. It places university law clinics on the access to justice landscape, with other providers, as part of the access to justice ecosystem.

26 clinic respondents recorded how many prior sources of advice their clients had accessed (Figure 6): 73\% (19 out of 26) had accessed one previous advice source; $15 \%$ (four out of 26) had accessed three previous advice sources; and
$12 \%$ (three out of 26 ) had accessed two previous advice sources. The data does not record how many clients will have accessed no other advice source prior to coming to the clinic but one clinic noted in their commentary that:

"A lot of clients have accessed no help at all prior to visiting us; they turn up at court not knowing where else to go as they cannot afford to see a solicitor and/or are not able to manage their own affairs to the extent that they could work out the most appropriate course of action for themselves." (clinic number 3)

This clinic operates a drop-in service at a local court, and we might therefore assume that the exposure of the clinic to previously unassisted clients would be greater than a clinic based at a more remote university campus. The referral relationship between clinics and other advisers, however, suggests that clinic clients are looking in the same, relatively standard places for advice as other advice seekers.

These findings indicate that clinics are not the main focus for advice seekers, and that the clinic relationship with other advice providers will therefore be a necessary part of clinics' networks. 


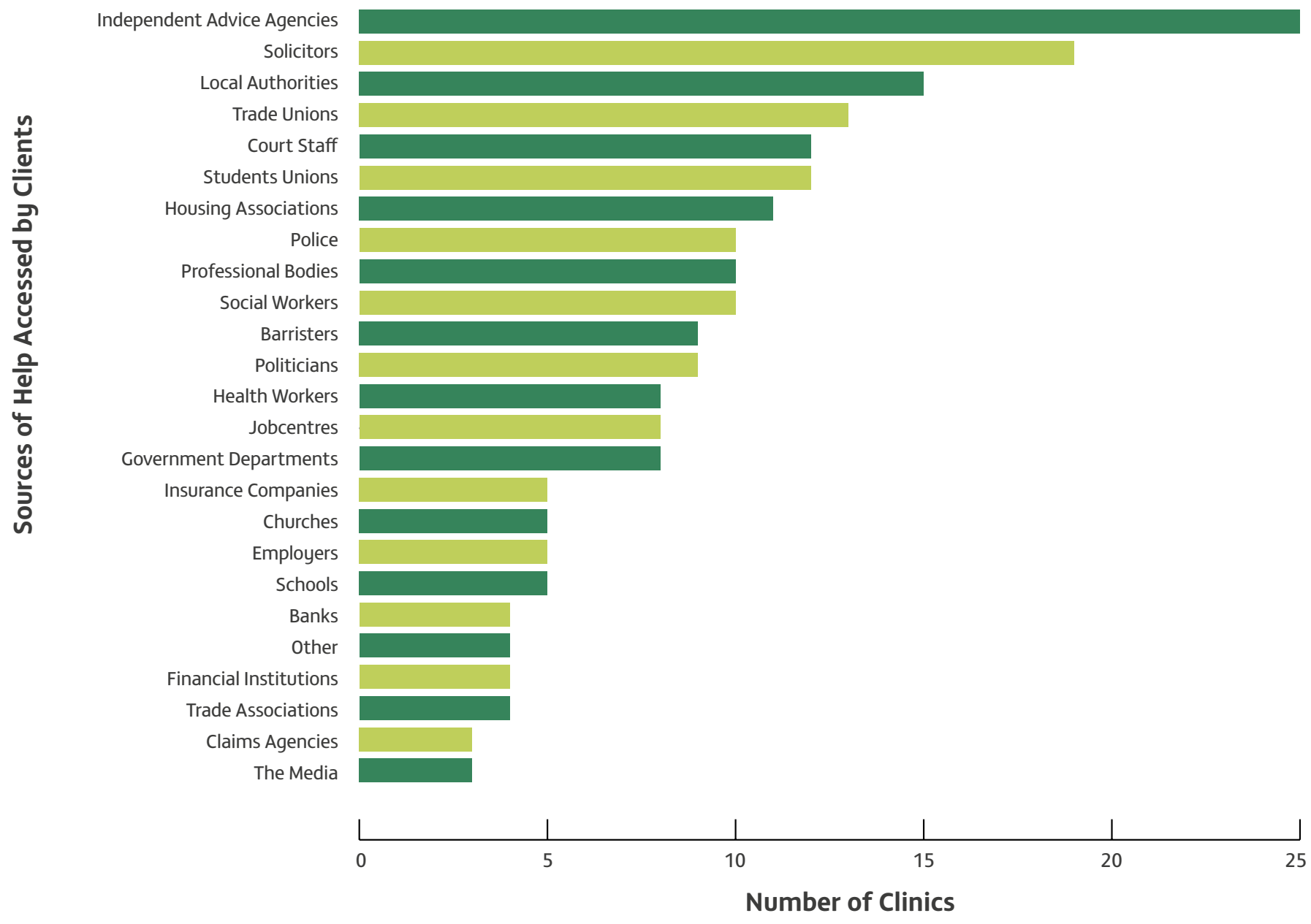

Figure 6: The most common sources of help accessed by clients prior to coming to the clinic

\section{Intervention points}

The survey also sought to identify at what stage in their advice seeking journey clients came to clinics. Of the 29 clinics who responded, 22 (76\%) stated that clients come after they have made some initial attempts to resolve the problem, a finding that would seem to correspond with the majority of clients having accessed other advice sources prior to attending the clinic. 12 clinics $(41 \%)$ said clients come when they know they have a legal deadline to meet, and 12 said clients come when they are at crisis point. While this is not unsurprising, particularly if clients are coming to clinics after seeking advice from up to three other sources, the case selection criteria of several clinics was based on their inability to meet urgent deadlines, reinforcing the limitations of clinics in responding to imminent legal need. One clinic noted that they received relatively few enquiries from clients facing immediate deadlines, and suggested that this may be because the university website made clear that such cases could not be supported by the clinic. Eight clinic respondents (28\%) said that clients come as soon as their problem arises. Five respondents (17\%) identified that clients come at all stages of their advice seeking journey, one of whom specifically noted clients coming post-adjudication to seek advice on appeals.
The findings are perhaps unsurprising, since they indicate that individuals do not adopt a consistent approach to dealing with their legal problems, but rather seek help at a variety of stages, from a variety of sources. This is part of why clinical legal education is valuable for students, since it contrasts the reality of individual approaches to legal problems with a more academic, sterile notion of linear solutions to discrete legal problems. However it also makes for more difficult access to justice solutions through law clinics since there is no singular point at which individuals might routinely be referred to clinics for legal assistance in a way that clinics can accommodate in line with their service limitations. This may be no different from the service limitations of existing legal advice providers but it does raise questions about how clinics might be systematically inserted into a client's path to justice. It also underlines the importance of clinic connections to other advice services, and the need to nurture relationships here that can be of benefit to clinic clients.

There is further, conceptual issue that the findings highlight, which is that the intervention points we seek to identify in resolving legal problems are themselves rooted in the view of problems and the attendant solutions as 'legal'. But perhaps rather than attempt to lead the way to law clinics as part of a legal solution, the evidence that 
is being presented through law clinics might be harnessed to identify alternative, non-legal intervention points. For this idea to take hold, there is a need to embrace the view that access to justice is not the same as access to a legal solution, particularly where those legal solutions themselves create difficulties for individuals - intellectual, practical and emotional difficulties that are connected to the legal process itself. In this analysis, justice is not measured by the same set of metrics or values that attach to traditional access to justice solutions but on how to make the pathway to redress less emotionally, financially, and temporally taxing. The role of CLE here is to train law students to identify the best solution rather than to prioritise the legal solution, and innovative research generated by this focus on the interdisciplinary nature of solutions to socio-legal problems can feed this educational focus. This approach offers a potential route for clinic development that may be more easily aligned with core university objectives.

\section{Barriers to justice}

Clinics were asked to identify the types of intellectual, practical and emotional barriers that clients faced, from a range of indicators derived from empirical research with tribunal users in relation to their legal journeys. ${ }^{61}$ All 32 clinics responded to these questions, but two responses were invalid. The remaining 30 responses identified that clinic clients faced the full range of intellectual, practical and emotional barriers that were indicated.

\section{Intellectual barriers}

Intellectual barriers were overwhelmingly identified as being met (Figure 7), with the majority of clinics (26 out of 30 , or $82 \%$ ) stating that clients faced barriers in understanding how decisions/problems can be challenged and in understanding the legal formalities, including language and procedures. $75 \%$ (24 out of 30 ) stated that clients had difficulty understanding if decisions/ problems can be challenged, and $72 \%$ ( 23 clinics) said clients had difficulties understanding the decision making process and understanding written information on legal entitlements and processes. $66 \%$ ( 21 clinics) said clients struggled with knowing how to complete relevant documentation and 53\% (17 clinics) said clients had problems with understanding the reasons why decisions have been made.

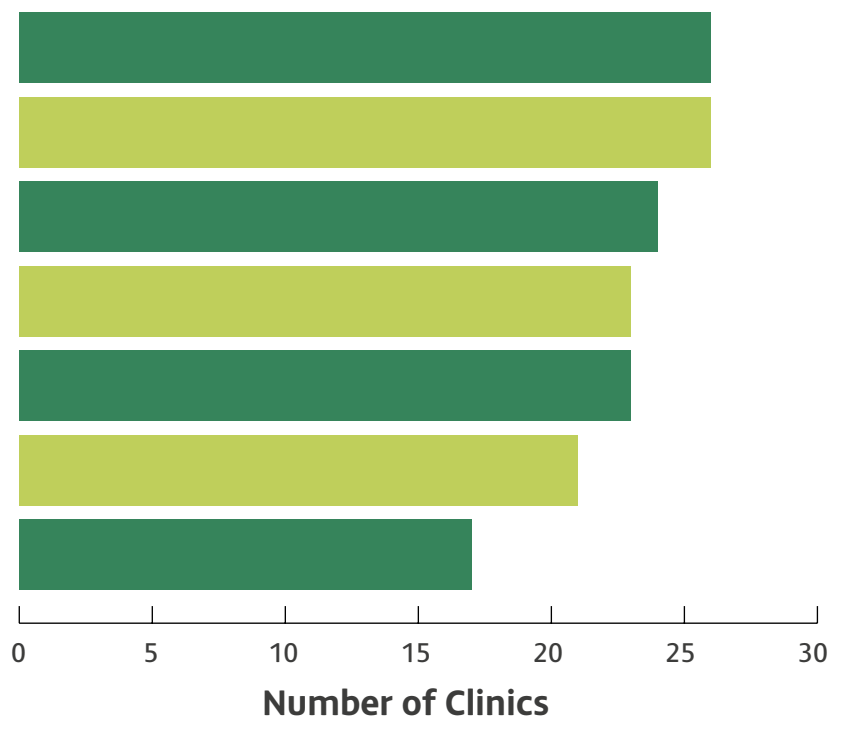

\section{Practical barriers}

A similar picture emerges in relation to practical barriers, with clients found to be struggling across a range of practical issues connected to their legal problems (Figure 8).

29 clinics (97\%) stated that clients faced difficulties knowing where to go for help/advice. This finding is in common with the research on difficulties individuals face in accessing legal support, which evidences that individuals do not seek legal advice in systematic ways, in part because they may not conceptualise their problems as legal problems. What is interesting here, however, is that clients are finding clinics, both through referral organisations and through self-referral, most likely on their second or third attempt to get help, matching their legal problems with student-focused, educational initiatives that offer a limited form of legal assistance and support.

26 clinics (87\%) stated that the cost of accessing other sources of help/advice was a practical barrier faced by their clients, as was the cost of securing expert/ supportive evidence, which was identified by 20 clinics (67\%). This reinforces earlier findings that the reduced financial circumstances of clients was regarded as prevalent by 11 out of 24 clinics, even though only 8 out of 32 clinics indicated that they specifically collected data on the financial circumstances of clients. A further practical barrier identified by 20 of the clinics was the long waiting times clients experienced in accessing 
sources of help or advice, a problem that becomes more acute when placed alongside the self-imposed limitation by clinics to only take cases with more distant deadlines. If delays are built into the client's journey to the clinic, the chances of clinics being able to assist on short timescales also reduce.

19 clinics also identified that clients face practical difficulties in knowing where to get relevant documents, such as social security benefit appeal forms. This is an elemental part of the justice system, relating largely (although not exclusively) to procedural issues that should not require specialised legal assistance: such forms are not designed to be completed with the aid of a lawyer, indicating that there is room here to reduce the practical barriers faced by individuals without relying on free legal assistance as the solution. Identifying how and where decision-making processes could be improved is something that can easily be built into CLE as part of its teaching and research objectives, getting law students focused on the most effective (rather than simply legal) solutions and developing research-based responses to systematic or regulatory processes.

13 clinics (43\%) identified physical barriers that clients faced in accessing help/advice. Again, this reinforces other findings in the access to justice literature where physical access, often related to difficulties faced by residents in more rural areas in accessing advice services based in urban locations, was a practical barrier. It also raises a specific question for university law clinics regarding their physical location, within suburban or sprawling university campuses, or within physical spaces that are not normally accessed by the public and which may appear intimidating or unfamiliar.

English language barriers were found to be prevalent by 12 clinics, which is perhaps lower than might be expected given that 16 clinics cover immigration, asylum and human trafficking: areas of work in which many clients will not have English as their first language.

Knowing where to go for help/advice

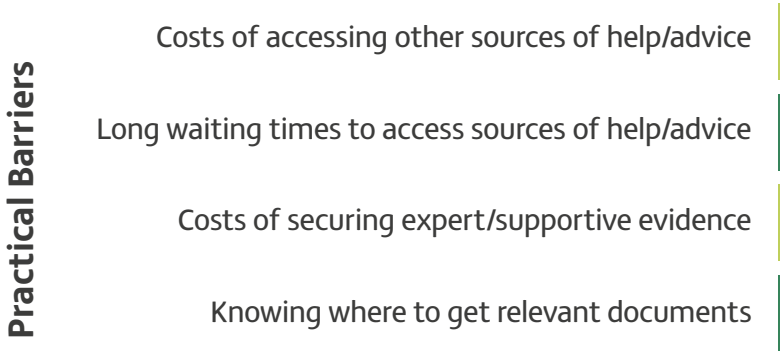

Physical access to sources of help/advice

English language barriers
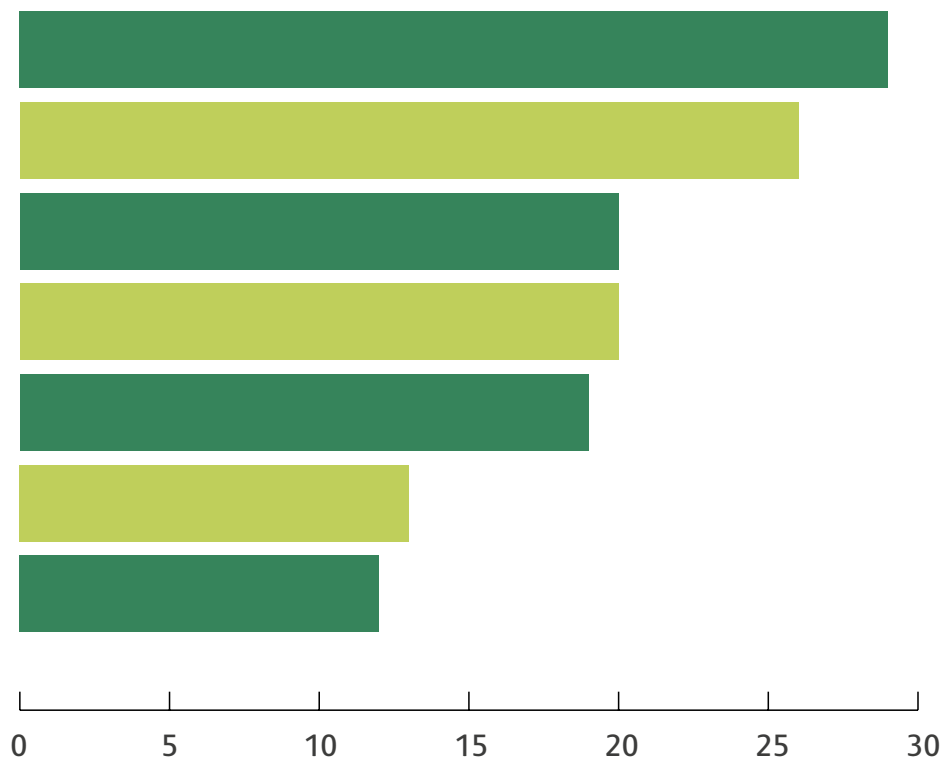

Number of Clinics

Figure 8: Practical barriers faced by clinic clients

\section{Emotional barriers}

As with intellectual and practical barriers, clinics indicated that clients faced a range of emotional barriers. The most prevalent difficulties were lack of confidence and stress, identified as prevalent by 27 clinics (90\%); anxiety and frustration, identified by 26 and 23 clinics respectively ( $87 \%$ and $77 \%$ ); anger, depression and fear identified as a problem for clients by 18 clinics (60\%); and 13 clinics (43\%) identifying that sleeplessness was a problem for clinic clients. 


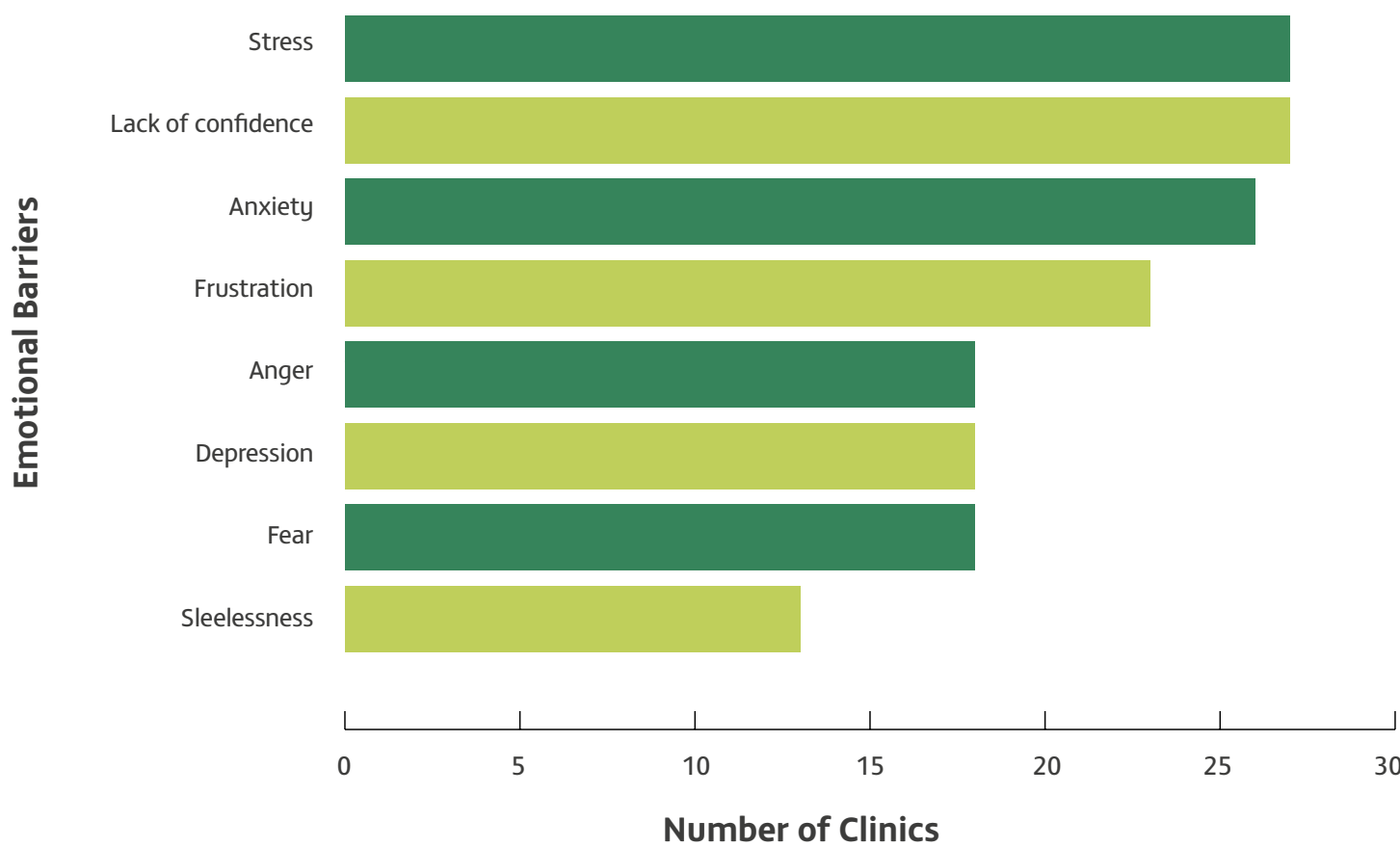

Figure 9: Emotional barriers faced by clinic clients

Arguably there is nothing surprising in these results, but once again they do serve to locate clinics within the traditional landscape of advice, confirming a profile of client characteristics and experiences that reflects the profile of other advice service clients, and indeed of individuals who do not secure advice but still have legal problems. The findings do not indicate the impact of the clinic on the barriers faced by clinic clients. It may be possible to adopt a working assumption that clinics can assist clients to overcome at least some of their intellectual, practical and emotional barriers, but further research is needed to understand the extent to which clients are enabled to deal with these barriers by clinics, or indeed whether clinics have any positive impact on these issues.

\section{Awareness and perceptions of clinics}

The practical difficulty faced by individuals with justiciable problems in knowing where to go for advice is borne out in this survey: 29 out of 30 clinics (97\%) stated that clients faced this difficulty. Yet it is also clear that clients are managing to identify clinics as possible sources of advice. The literature makes clear that one of the difficulties individuals have in accessing support is related to their inability to conceptualise their problem as 'legal'. ${ }^{62}$ For many, 'legal' problems are more likely to be regarded instead as housing problems, health problems, education problems - problems that are not viewed through the prism of law, but through the prism of life experiences, clustered among other problems in other domains of life. For a client to be able to identify a university law clinic as a potential source of help may suggest that they need to understand their problem has a solution, that the solution is connected to law, and that the legal solution can be accessed through a university Law School. The reality is perhaps slightly different; clinics identified a range of ways in which clients are made aware of their service, yet the most common method (cited in 14 out of 26 responses, or $54 \%$ ) by which clinics said clients became aware of their services was through internet searches with the clinic's web presence hosted by the university website, and clinics suggesting that the search term would be 'free legal advice'. Other terms may be used but this suggests a randomness - and a lack of quality control - to the selection of clinics as advice providers, which is perhaps in keeping with the research evidence that individuals come across advice sources by luck or chance. ${ }^{63}$

Clinics also identified that they raised awareness of their service through advertising, with $59 \%$, or 19 of the 32 clinics stating that they advertised the clinic services to the public, mainly through traditional media forms: leaflets, posters, local news outlets. The question that might be asked is whether, having advertised its services, the clinic is obliged to deliver, and if so, what it is obliged to deliver: legal education? Access to justice? A complementary provision of both? The survey identified that clinic clients often had misperceptions about what assistance the clinic could provide. Five out of 30 clinics $(17 \%)$ stated that clients fully understood what the clinic did, and five stated that clients had only a limited understanding. 20 out of 30 clinics (67\%) stated that clients had a reasonable but incomplete understanding with the most common misperception being the nature of the service being offered. In particular, clients thought - incorrectly - that the clinics offered a full service, namely: immediate and full advice on all problems; full 
casework provision, including representation that would continue regardless of the "twists and turns the case takes" (clinic number 14); open at all times; and imposing a financial charge for the service. Only one clinic identified clients having misconceptions about law students, believing that the student clinicians were qualified lawyers. When asked whether clients had concerns about relying on advice from law students, only 3 out of 31 clinics (10\%) identified concerns, indicating clients' initial reluctance to accept advice from a student, and a desire to go straight to the student's supervisor instead.

$84 \%$ of clinics (26 out of 31 ) collected client feedback, with 26 out of 27 clinics ( $96 \%$ ) identifying the objective of feedback being to improve service provision. 19 out of 27 clinics (70\%) collected feedback to let students know what clients thought of their work, reflecting the duality of purpose of clinic services: to enhance student education and provide a service delivering access to justice. A third of clinics (9 out of 27) sought feedback to identify need, with one clinic identifying the publicity value that feedback could provide.

\section{Clinic objectives}

All 32 clinics surveyed identified a broad set of objectives for their clinics (figure 10). Assisting local communities was an objective for 29 clinics (91\%). Meeting unmet legal need, improving student employability, and developing professional capacity in law students were each objectives for 27 clinics (84\%). Delivering access to justice was an objective for 24 clinics (75\%); raising student awareness of the impact of legal problems was an objective for 21 clinics (66\%); and 20 clinics had an objective of fostering a sense of social justice among law students (62\%). 13 clinics $(41 \%)$ had an objective to improve client participation in legal processes and two clinics (6\%) had specific objectives relating to improving student education.

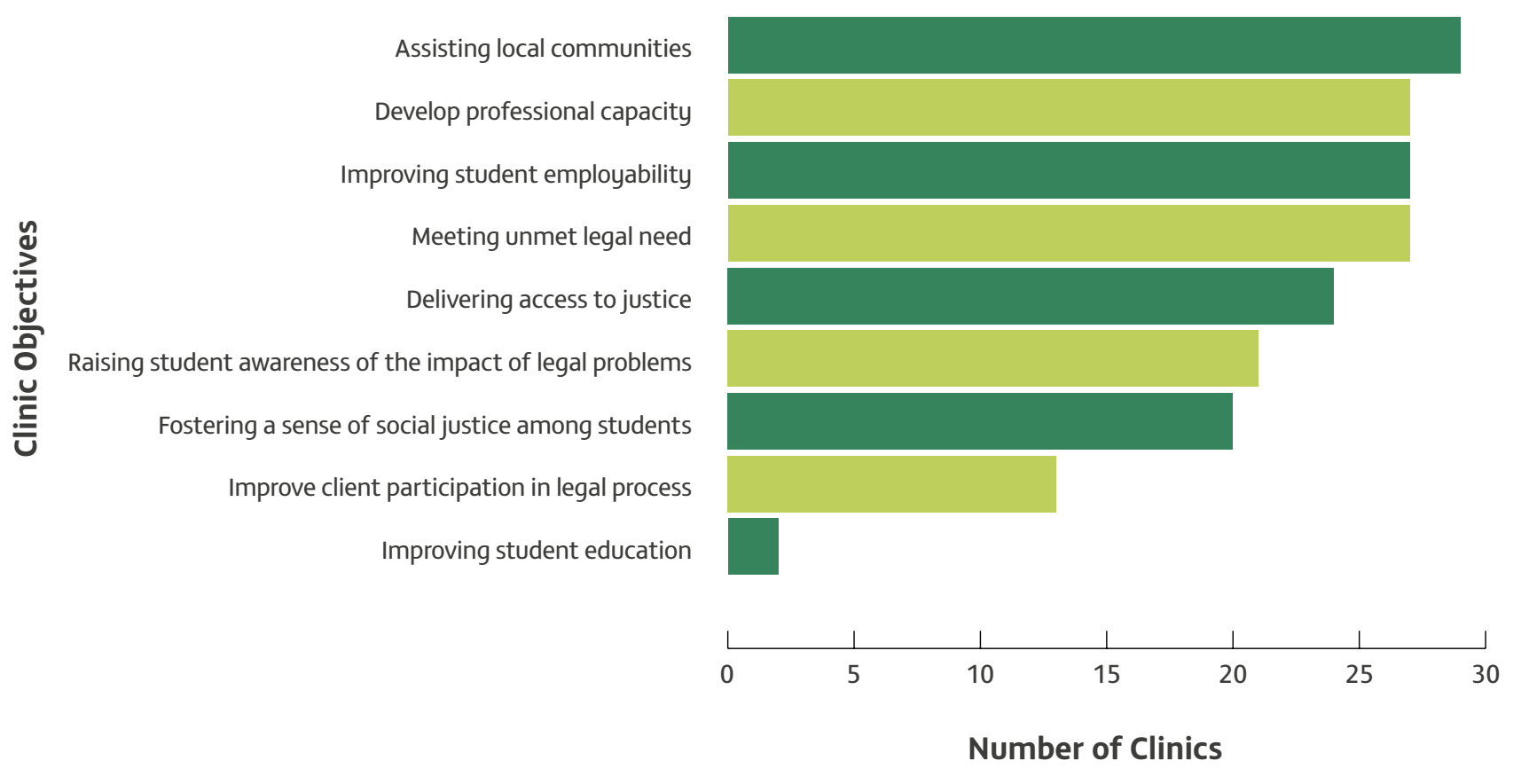

Figure 10: The range of clinic objectives

As Figure 11 shows, when asked to rank these objectives, to identify the three most important ones, the top ranked objective was to improve student employability (ranked as most important by $58 \%$, or 18 out of 31 clinics), followed by the objective of developing professional capacity in law students (ranked as most important by $47 \%$, or 14 out of
30 clinics), and then to assist local communities (ranked as most important by $42 \%$, or 13 out of 31 clinics). A close fourth was to deliver access to justice (ranked highest by $39 \%$, or 12 out of 31 clinics) and then to meet unmet legal need (ranked highest by $33 \%$, or 10 out of 30 clinics). 
Improve student employability

Develop professional capacity in law students

Assist local communities

Deliver access to justice

Meet unmet legal need
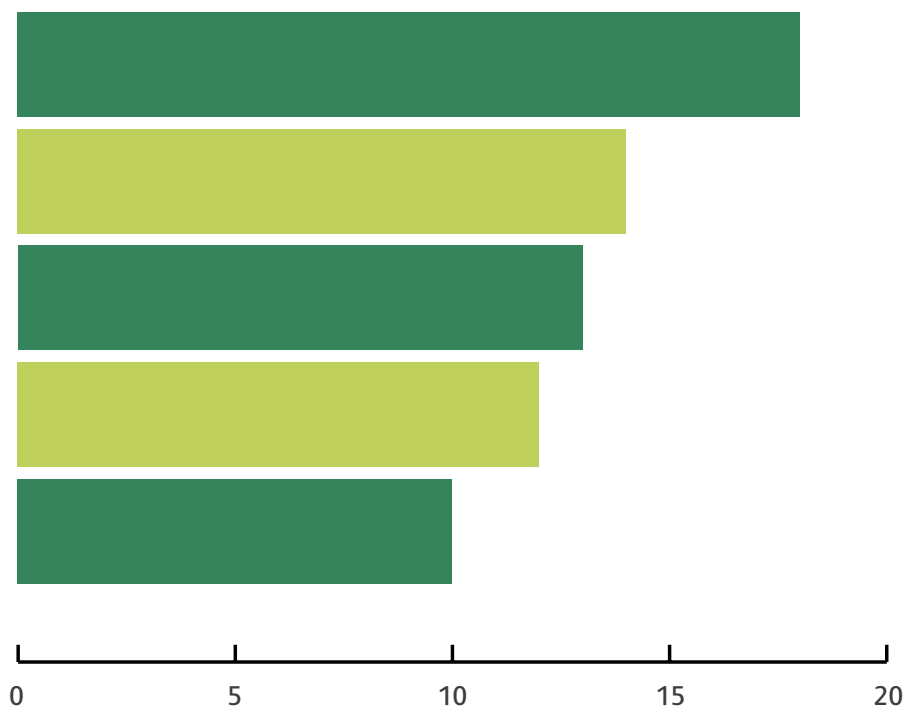

Number of Clinics

Figure 11: Clinic objectives ranked in order of importance to clinics

The ranking reveals the potential tension between two main objectives that are evident for all clinics: education and justice. 22 out of 32 clinics (69\%) stated that a university Law School should be an access to justice provider, with the main reasons being that this was an important part of a Law School or university ethos and an important part of legal learning (as stated by $86 \%$, or 19 out of these 22 clinics). 13 and 15 clinics ( $41 \%$ and $47 \%$ ), respectively, gave reasons of making good use of student talent, and being a good pedagogic initiative. 12 clinics $(38 \%)$ took the normative view that there was a legal need for Law Schools to assume this role; nine out of 22 clinics (41\%) stated that there was a moral obligation to provide assistance (figure 12). Two clinics (6\%) identified concerns based on the clear view that it was the state's responsibility to provide access to justice and a university's responsibility to provide education. One respondent made clear that there should be no compunction on universities to be an access to justice provider, unless they wished to be so, while one accepted that the state did not always meet its responsibilities fully and that consequently an access to justice gap exists.

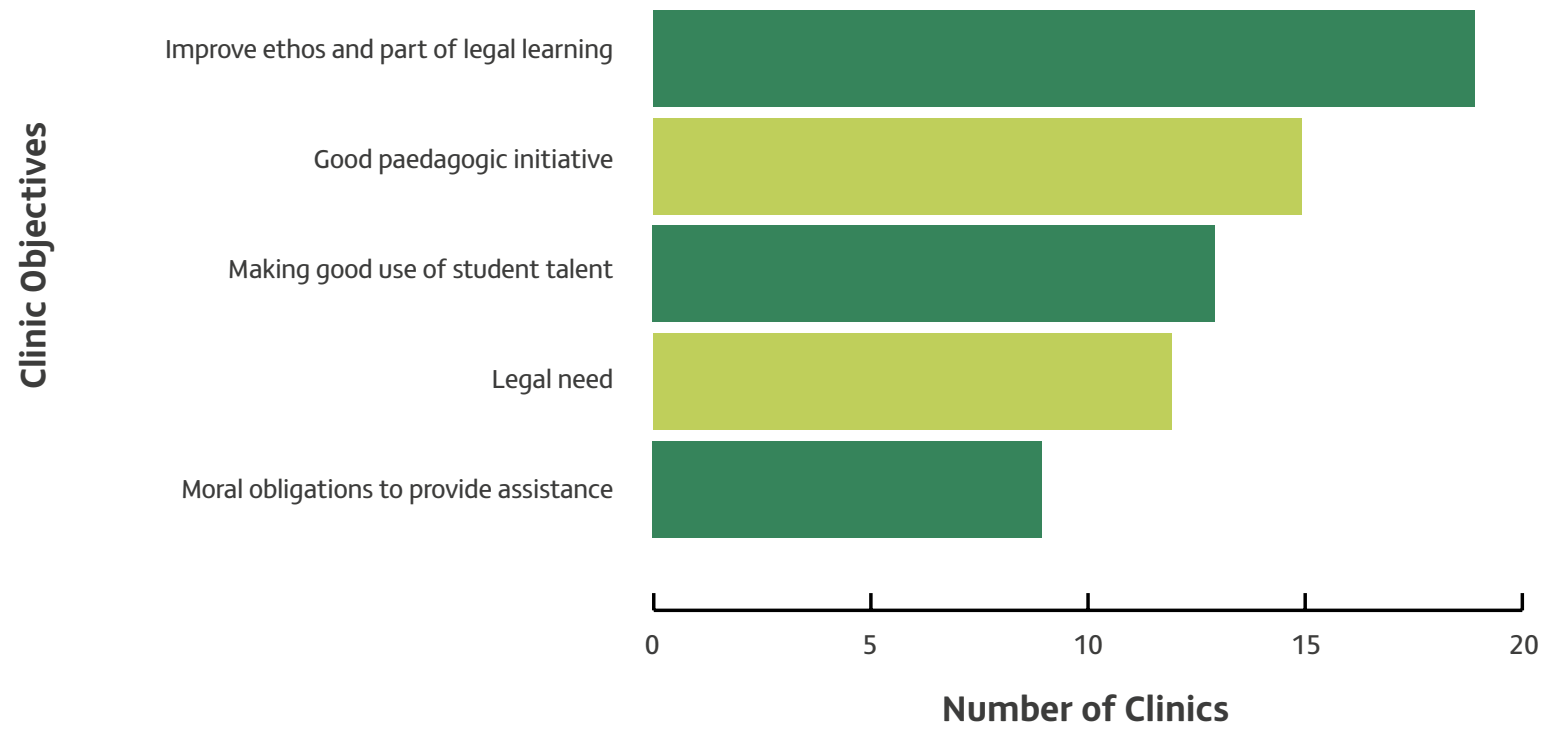

Figure 12: Reasons why clinics feel Law Schools should be access to justice providers

Of the ten clinics that stated a university Law School should not be an access to justice provider, there was a clear sense that a law clinic should prioritise education; that it was not equipped to be an access to justice provider - particularly in relation to the volume of cases requiring assistance and the time and resource intensity required to assist clinic clients; and that it was the state's responsibility to provide access to justice. One clinic felt that an access to justice role would interfere with the work of private sector lawyers. The bias inherent in the sample, however, needs to be recognized. The respondents were from Law Schools which had each established a law clinic (and in some cases, 
multiple law clinics) so it may well be that these are the Law Schools which already identify a social justice mission for themselves. The Law Schools that have not established law clinics - and who are therefore not included within this survey - may have taken a view that the School's mission is not about providing social justice, or delivering an access to justice focused service.

Overwhelmingly, however, clinics considered themselves to be access to justice providers, with $90 \%$ of respondents acknowledging this. of the $10 \%$ (or 3 clinics) that did not consider themselves to be access to justice providers, only one gave a reason for this, stating that the clinic offered a "very simple, basic service", suggesting that the inability to ascribe an access to justice function to the clinic was pragmatic rather than principled. Of the 27 clinics that did consider themselves to be access to justice providers, the reasons were equally pragmatic: the clinics provided advice and, therefore, access to justice to those who were unable to access advice elsewhere. This pragmatism extended to the recognition of clinic limitations in delivering access to justice - in terms of service delivery, volume, and the need to prioritise student education.

\section{Conclusion}

The findings evidence the existence of a range of law clinics in university Law Schools, working in diverse areas of law, offering - generally - a limited service, but one that often connects to other access to justice providers. The work of university law clinics needs to be understood properly in order to assess the role that clinics can play in delivering access to justice, and the parameters within which this form of justice service can be delivered. The access to justice ecosystem is intricate and complex and this report aims to draw some conclusions on how clinics form part of this ecosystem and how their potential can be realized within the very real constraints in which they, and other legal service providers, operate. 
Part 3 - Conclusions and recommendations 


\section{The role of universities}

This report evidences the tension that exists for university law clinics between serving a broad access to justice focused mission and the need to prioritise the objectives of legal education that has marked the development of clinical legal education in the UK and that continues as a dominant feature of the debate about the role of clinical legal education in the UK. The research from this report corroborates the split in the legal academy about the purpose of clinical legal education, and indeed the functions of Law Schools and of universities, with respondents to the survey oscillating between the perspective that access to justice is not the business of universities but of the state, and the view that universities should embrace the critical role that Law Schools can play in meeting the access to justice needs of their local communities. These tensions can be reconciled where clinics see themselves as inevitably providing access to justice, by virtue of the legal support they give to individuals, but this is caveated in principle and practice that the access to justice focus cannot displace the state's duty to provide access to justice for its citizens; that there are limitations on the access to justice provision that clinics can fulfil; and that legal education will inevitably take priority over access to justice where the two objectives conflict.

\section{In part this conflict stems from the increased} marketisation and documented rise in the consumerised demands of fee-paying students. Universities competing for students, and the fee income that students bring, means that there is a need to focus on responding to student demand as well as shaping student expectations. The dilution of the concept of (higher) education as a social right, and the developed perspective of its function as a vocational route has inevitably altered the ability of universities to react to external demands. The legal academy has long been divided between the objectives of a broadly based, undergraduate curriculum which uses law as the tool to teach critical thinking, to develop analytical capacity which is further refined through focused postgraduate study, and the demands of legal professional training in which core skills, including the application of law to practice, is seen as critical throughout a student's legal education. These tensions are exacerbated by the different rating mechanisms for teaching and research, and the different attitudes to these activities within individual universities. While the two core functions are often complementary, their different profiles have resulted in academics and institutions having to serve different masters, each with specific resource demands: research as ranked (and directly financially rewarded) through the national Research Exercise Framework while teaching quality is subject to a different set of benchmark exercises, with different, often more indirect financial consequences. Numerous other academic demands also compete but the research-teaching nexus is one of the most critical for institutions and their staff. Consequently, anything that adds value to these elements may be more likely to attract institutional support, but where one core activity is prioritized over the other then these elements can be competing rather than complementary.

There is a fundamental question that the research highlights, which is concerned with the role that universities do, or should, play in society. Their function of delivering education through teaching and research is broadly understood, but what is not clear is the extent to which universities should serve wider social justice objectives, how they could meet such objectives and how they might be supported in this function. The specific question for this research is about whether universities should assume a role in meeting access to justice needs which in turn raises a central question around which this debate revolves over what the state's role is in providing access to justice, and how it should deliver on its obligations to citizens seeking justice. While this report evidences contradictory responses about the role of universities in providing access to justice services, there is consistency among respondents that the state has ultimate responsibility for enabling individuals to access justice and consistency too that university law clinics are not adequate substitutes for a state supported advice structure. The bigger questions on the role of the state, and the role of universities in meeting societal needs, are cultural, philosophical, economic, social and political questions that go beyond the remit of this report, but which need to be considered as part of the context of these research findings and the potential for the development of access to justice provision.

\section{Delivering access to justice through universities}

The research findings demonstrate that university law clinics form part of an intricate ecosystem of legal advice in the UK. The range of areas of law covered by clinics is diverse, and not necessarily predictable since the clinic focus is more likely to be aligned to Law School expertise than demonstrable legal need. The services provided are often basic but range from establishing the legal issue, to offering written legal advice, to providing specialist legal representation. The number of cases varies widely between clinics but the overall number of clients helped on an annual basis is substantial. The network of university law clinics in the UK has continued to grow since the 1990s, creating a greater geographical spread across the UK. While most clinics are based in or around predominantly urban university campuses which may be unfamiliar to the general public, some clinics do situate themselves in more client-friendly environments, including shopping centres and court buildings, and most clinics attempt to engage with the public to raise awareness of the services they provide and the assistance they can offer. The research does not provide any evidence that clinics are any better than other service providers at meeting the needs of hard to reach populations. Instead, the same 'advice seekers' and self-helpers who make their way - eventually - to other legal services will also end up at university law clinics, even where the client problem does not match the clinic's 
service, and the research evidences different arrangements by clinics to direct clients to more appropriate sources of help.

The research provides ample evidence of positive and fruitful relationships between law clinics and other legal services, and this interconnectedness is a critical component in understanding the role that clinics can play in delivering access to justice. The majority of clinics make connections with other service providers, with the majority of collaborations and referrals taking place with independent advice organisations, solicitors, barristers and court staff, but extending substantially beyond this. Clinics describe the mutually beneficial nature of these relationships, and the research indicates that clinics can complement existing legal services, although there is no evidence as to the resource cost to the external organisations, or indeed their direct views on the benefits of such partnerships. What is evident, however, is that the advice ecosystem is complex and that the role of clinics can vary as the ecosystem changes, but that variations in the role of clinics may not be directly responsive to changes in the broader ecosystem.

Most of the problems faced by law clinics in delivering legal support are not peculiar to them, and point to a need to configure clinics in discussions about how to match clients to the right service, and the need to develop and protect effective relationships among different legal service providers. Stronger relationships between clinics and external providers would seem to indicate better overall services for clients, but improving relationships across the legal advice sector - may be about enabling co-operation rather than fostering competition. The specific mention made by some clinics about the need to avoid competing with other service providers speaks to the culture of competition rather than co-operation that clinics see as existing in the legal sector. There is also clinic awareness of the difficulties faced by some organisations in maintaining sufficient resources to meet legal need and the difficulties this generates for clinic clients and those beyond the clinic's help. Sommerlad and Sanderson highlight the impact of competitive practices on third sector organisations as potentially destructive of mission, and detrimental to the different layers of advice that need to be protected to maintain the balance of the ecosystem, particularly in terms of expert advice and associated policy development. Clinic competition with private sector providers may also be destructive of clinic mission, which inevitably has a focus on the future employment of student clinicians, and the research demonstrates that clinics are keenly aware of the need to walk a fine line here, to avoid biting the hands that feed them, and to be supportive rather than destructive of sectoral developments. In any sector, there is a need to understand the range of different roles that are played, to appreciate the value of linkage and support, and to grasp the impact of changes to these profiles, to these organisations, to the overall service that can be provided when parts of the ecosystem are removed. The role that external organisations play in supporting clinic work and development is seen by clinics as critical, suggesting that the impact of changes to these external organisations is more likely to reduce the capacity of clinics to deliver access to justice, rather than to hope that clinics can provide any replacement service.

\section{Limitations of university law clinics as access to justice providers}

The research also highlights the limitations of university law clinics in providing access to justice. Clinic casework is limited by a lack of capacity - in terms of staff numbers and expertise; physical and financial resources to support or develop casework; student availability, knowledge, ability and commitment; and the need to manage clinic caseloads to match student-focused objectives within these parameters. The service models offered by clinics vary considerably, with the model of support matched to Law School requirements rather than to legal need. The research evidences the misperceptions by clinic clients about the nature of the service being provided, with clients not fully aware of the clinic's limitations in progressing their legal problems. In addition, clinics are not always obvious or visible on the legal landscape and are predominantly student-centred and staff driven. The consequence is that clinics may not be able to help the clients who find them, either because of a lack of capacity, or fit, and without any guarantee of connecting the client to a more suitable provider, with the risk therefore of exacerbating referral fatigue and the individual's sense of frustrated resignation: clinics themselves could become a further barrier on the path to justice unless clients are properly directed and adequately assisted.

These limitations mean there is no singular point at which individuals might routinely be referred to clinics for legal assistance. Instead, the entry point will vary according to the individual clinic's service model, which may not have been developed in line with other local service provision, and which will itself be subject to variation depending on internal university demands. This may be no different from the service limitations of existing legal advice providers but it does raise questions about how clinics might be inserted systematically into a client's path to justice. It also highlights the importance of external partnerships for clinics - where partners are aware of what the clinic can provide and how to make, or receive, appropriate referrals but here too the dependence on external partners creates vulnerabilities for clinics, particularly where those external partners are themselves vulnerable. The impact on the legal ecosystem of removing what might seem to be minor or remote support mechanisms may cause considerable detriment if the consequence is to reduce the layers of expertise that make the ecosystem effective and on which other parts of the ecosystem depend.

There are also strategic issues that operate to limit clinics. The development of university law clinics in the UK has been ad hoc, tied to individual and institutional academic 
objectives rather than access to justice agendas, with the overriding need to serve core university functions, and associated academic demands. While clinics can lay claim to enhancing pedagogic developments and employability agendas, as yet there is insufficient evidence of REFstandard research being developed, despite the potential for empirical work and associated policy impact. A missing research focus may create institutional vulnerabilities for clinics, where the pedagogically focused access to justice benefits are not seen as an adequate trade-off. Universities are publicly funded institutions, but their funding is connected to education - in all its manifestations - and the proposal that universities should also deliver access to justice services, or should use their educational mission as the means to deliver access to justice, may have only limited purchase in the face of more pressing institutional demands.

\section{Development potential for clinics as access to justice providers}

The relationship between clinics and external providers is one of the most critical findings of this research, and indicates that the development potential for clinics is intimately connected to the need to protect their external partners. Clinic work will be more likely to meet the needs of clients where the external advice environment is healthy - both in terms of clinics working through external providers for appropriate case referrals, supervision and other resources, and in terms of clinics being able to assist clients beyond the service capacity of the clinic, so that clinics form part of the client's path to justice which can then be extended through external partners. Enhancing and supporting clinic relationships with other access to justice providers therefore seems a critical aspect of developing the access to justice function of clinics, which necessarily indicates a need to enhance the capacity of external partners to collaborate with clinics. The research evidences the value to law clinics of these partnerships, and the consequential value to clients, but further research is needed to substantiate the value of clinic partnerships to external providers. In addition, the research does not make any comprehensive finding on the impact of clinics on the intellectual, practical and emotional barriers faced by clients, and the development of clinics should be informed by further research on the extent to which clinics are able to enhance legal capacity.

Developing the potential for law clinics must also take account of the service model offered by clinics, which tends towards the more basic, general advice model, with relatively few clinics able to provide specialist legal assistance. Developing clinic capacity therefore, will also involve enhancing third and private sector capacity for complex, specialist cases. The role of specialist, expert advice is to unlock the complexities of individual, strategic or test cases. Some clinics may be able to take on the complex, borderline cases that general advisers are unable to take, where such cases offer educational value, but there is no evidence of clinics taking a strategic approach to such cases, or of case selection policies identifying or prioritising test cases. Sommerlad and Sanderson's research evidences the critical role of expert advice in supporting general advice services, and clinics can be seen to be equally dependent on expert and specialist advice in advancing client cases.

In addition, the development of law clinics can include harnessing their potential to draw lessons from frontline casework (of clinics and external partners) to feed into research and policy agendas. This requires advancing the relationships with potential policy partners, as well as enhancing university support to develop clinic casework towards research and policy outcomes. Clinics have made valuable and productive connections with a range of legal service providers, and these relationships could be built on to understand systematic and operational barriers to justice and to pilot and develop innovative solutions, but this may place additional demands on external organisations to feed through frontline learning. The research and policy potential for clinics, therefore, includes the need to enhance the capacity of external partners to feed into policy-focused consultations and research. Such capacity cannot be assumed, as Sommerlad and Sanderson's research indicates, but has the potential to enhance not just academic research on access to justice, but also the evidence base for policy makers in identifying best practice and possible solutions to access to justice problems.

The support from universities will play a critical role in supporting or restricting the development potential of law clinics, which in turn may require support for universities to align their core objectives to access to justice. Where individual institutions see pedagogic claims as being substantiated and research potential being reached, they may support clinics to progress core institutional functions, but there is no basis on which this assumption can be made for all universities and no guarantee that universities will enable clinics to meet their potential here. The support for universities to expand their core focus may be something that can be generated externally - through government departments with responsibility for justice, higher education or employment, for example - or through greater integration of CLE within public funding allocations for higher education institutions, or through a philanthropic focus connecting innovations in access to justice with university research. Ultimately, this goes to a bigger question about the function of universities - many of whom already adopt an inclusive, outward facing approach - and the ways in which the state can support broader societal objectives through universities, but without this debate being taken forward it may be naïve to assume that universities will, or can, readily incorporate the delivery of access to justice as part of their institutional mission. 


\section{Recommendations}

Flowing from the research findings and analysis, a number of recommendations can be made:

\section{Recommendations}

1. Understanding the value of clinic partnerships to external organisations and advisers will be a necessary part of assessing the role that clinics play within the advice ecosystem. Further research should be undertaken to assess the value of those partnerships to external providers.

2. The impact made by clinics on the intellectual, practical and emotional barriers experienced by individuals in their attempts to resolve their legal problems needs to be understood. Specific research with clinic clients should be conducted to measure the extent to which clinics are able to enhance the legal capability of their clients. This research should include a focus on the impact of clinics not being able to offer a full legal service to clients, and the consequential impact of any collaborative, referral or signposting arrangements that clinics put in place for clients.

3. Clinics do not adopt case selection policies that prioritise complex, strategic or test cases, and they are reliant on expert and specialist advisers to be able to progress these types of cases. The role of expert and specialist advice should be protected within the advice ecosystem to enable clinics to offer the most effective form of legal support to their clients.

4. The relationship between clinics and external service providers is of critical importance and should be enhanced. A mapping of service provision across the UK, which includes the services delivered by university law clinics, would assist in establishing how these services interact, the limitations and scope of service provision and the consequent gaps that exist. It would also provide further insight into the significance of law clinics as a proportion of overall advice provision.

5. University law clinics offer considerable potential to capture original empirical data and observe social phenomena that can be mined for research purposes and translated into policy impact. This research can be based on the casework of external partners, as well as clinic casework, but the capacity of external partners to feed into policy-focused consultations and research should be enhanced so that policy makers are able to benefit from this responsive analysis of access to justice barriers.

6. University law clinics also constitute a unique environment in which to test and develop innovative solutions to legal problems, that can draw on expertise in cognate areas within universities, from psychology, to philosophy, to communications, to design, to IT. Funding bodies, particularly those with an interest in access to justice or in the application of crossdisciplinary innovations to social problems, should identify funding streams designed to support pioneering research in these areas.

7. If universities are to play a role in developing the access to justice potential of their law clinics, there should be external support from government to enable universities to align their core activities with this role, and to receive appropriate recognition for their work. This could include reassessing the funding allocations for teaching clinical legal education, providing additional funding for enhanced employability outcomes, and creating REF-focused research initiatives to connect researchers to law clinics.

8. Justice departments could work directly with universities to support Law Schools in being able to offer law clinics in areas of legal need, through direct funding to university staff focused on casework supervision or development planning, or indirectly through funding student support to increase the ability of students to deliver casework.

9. University law clinics could also be supported by other government departments whose policies and practices may be contributing to increases in legal need, for example through regulatory changes to social security entitlements or special educational needs provision, particularly if clinic-focused research was designed to identify systematic improvements in decision-making processes.

10. While law clinics are split on whether their mission is to provide social justice or enhanced educational experiences, there is a recognition by clinics that their work does deliver access to justice for clients, and that students are part of this process of meeting access to justice needs. Further research should be conducted to establish the impact of law clinics on developing a social justice ethos among law students, and in particular on developing student attitudes towards pro bono activities as part of the role of lawyers.

\section{Conclusion}

There is much to recommend the expansion of the clinic movement in the UK - from a student perspective, a university perspective, a stakeholder perspective and an access to justice perspective. This research has sought to identify some core features of UK university law clinics to understand better their potential contribution to access to justice. The strategic objective of law clinics is difficult to discern at times, given that clinic development has not always flowed from access to justice objectives, and indeed the research indicates that clinics are not always clear what their founding mission was, or is. The research has sought to put some shape around these ad hoc academic developments in clinical legal education to assess their relationship to access to justice objectives. The research reveals that clinics offer a range of legal services, in a range of legal areas, and work with a range of other support services that clients rely on to progress their legal problems, but that the priority focus of clinics is student-centred, 
that clinics depend on the external advice environment to develop and progress cases, and that they are vulnerable to changes in institutional support. Further research is needed to understand fully the value that university law clinics bring to an access to justice agenda, not least in being able to measure the value to clinic clients and external partners, and in understanding the role clinics might play in developing a social justice ethos among law students as future lawyers, but what is now clear is that university law clinics function as part of a complex advice ecosystem that supports the potential for individuals to access justice. 
Annex 1:

Clinical Legal

Education Survey

Questions 
Clinic Name:

University:

3 Director/s:

Q4 Website address:

25 How many staff does the clinic have?

\begin{tabular}{l}
$\square$ Academic $\square$ Clerical/Administrative $\square$ External Supervisors \\
$\square$ Others (please specify) \\
\hline
\end{tabular}

Q.6 Approximate number of students participating per year:

$\square$ Undergraduate __ $\square$ Postgraduate __

How long has the clinic been established?

Q8 Approximate number of clients and/or cases per year:

Q9 In the past three years, has this number:

$\square$ Increased $\square$ Decreased $\square$ Remained fairly constant

Q10 If the number has changed, can you suggest why this is the case? (e.g. change in demand for clinic services; increased/decreased clinic visibility/change in clinic capacity; change in academic staffing) 


\section{Q11 In the last three years, have enquiries/referrals:}

$\square_{\text {Increased }} \square_{\text {Decreased }} \square_{\text {Remained fairly constant }}$

\section{Q12 If the number has changed, can you suggest why this is the case? (e.g. change in demand for clinic services; increased/decreased clinic visibility/change in clinic capacity; change in academic staffing)}


Q14 Areas of the law covered (please tick all that apply)

$\square$ Asylum

$\square$ Commercial

$\square$ Consumer

$\square$ Criminal

$\square$ Education

$\square$ Family

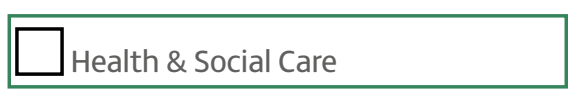

$\square$ Housing

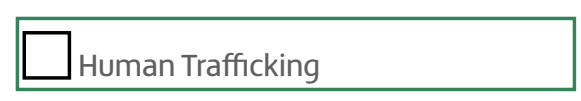

$\square$ Immigration

$\square$ Security

$\square$ Others (please specify)

Q15 For the purpose of this survey, collaboration is defined as clinics working with other individuals/organisations on a client's case In order to enable the clinic to deliver its services, does the clinic have formal collaborative arrangements with any of the following (please tick all that apply)

\begin{tabular}{l}
\hline Solicitors \\
\hline Barristers \\
\hline Independent Advice Agencies \\
$\square$ Others (please specify)
\end{tabular}

\section{Q16 In order to enable the clinic to deliver its services, does the clinic have informal collaborative arrangements with} any of the following (please tick all that apply)

\begin{tabular}{l}
$\square$ Solicitors \\
$\square$ Barristers \\
\hline
\end{tabular}

$\square$ In-house Lawyers in external organisations

Independent Advice Agencies

$\square$ Others (please specify)

Q17 Briefly outline any value these external collaborators bring to the clinic: 
Q18 Briefly outline any value the clinic adds to the services of these external collaborators:

Q19 For the purpose of this survey, referral is defined as clinics handing a client's file on to another organisation/ individual who has agreed to help the client Does the clinic have onward referral arrangements with other providers to deal with client issues not covered by the clinic?

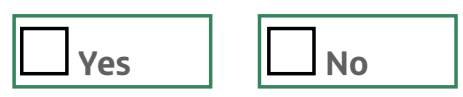

\section{If No Is Selected, Then Skip To Do you signpost clients to other rele.. If Yes Is Selected, Then Skip To Are these referral arrangements:}

Q20 Are these referral arrangements:

$\square$ Informal $\square$ A mixture of formal \& informal

Q21 What groups/agencies are clients referred to (please tick all that apply)

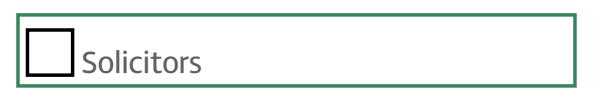

$\square$ Barristers

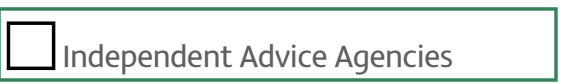

$\square$ Local Authorities

$\square$ Police

$\square$ Health Workers

Trade Unions

$\square$ Professional Bodies

\section{$\square$ Employers}

$\square$ Insurance Companies

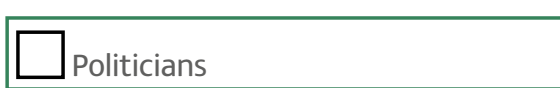

$\square$ Social Workers

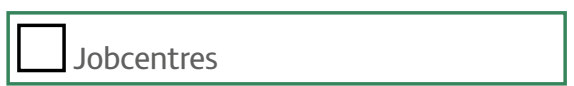

$\square$ Financial Institutions

$\square$ Court Staff

$\square$ churches

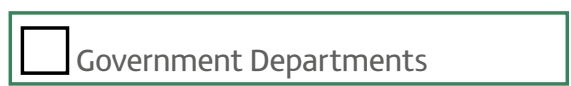

$\square$ Claims Agencies

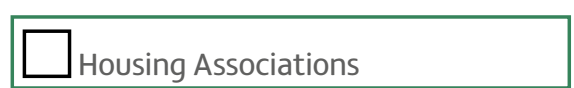

$\square$ The media

$\square$ Banks

$\square$ Schools

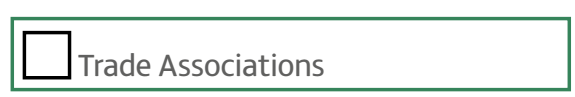

$\square$ Student Union

$\square$ 
Q24 For the purpose of this survey, signposting is defined as identifying other potential organisations/individuals who may be able to help the client. Do you signpost clients to other relevant service providers if the clinic is unable to assist with a client's problem?

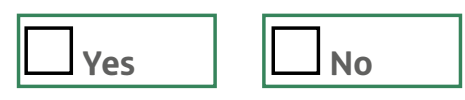

Q25 How is your clinic funded? (please tick all that apply)
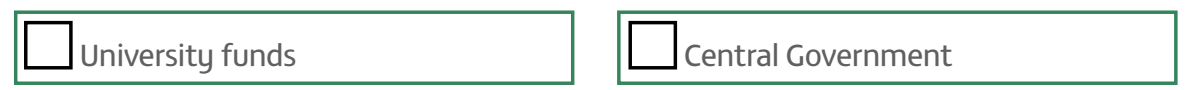

$\square$ Charitable Trusts

$\square$ Local Authority

$\square$ Research Councils

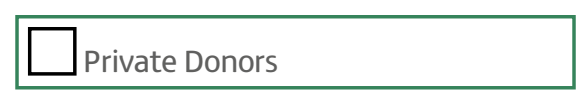

Others (please specify) 
Q26 Where funding comes from external (non-University) sources, what activities are covered by these funds? (please tick all that apply)

$\square$ Physical Resources

Student Scholarships and Support

$\square$ Research Activities

$\square$ Discrete Projects

Costs that would be incurred by clients

Others (please specify)

Q27 What data is collected on clinic clients? (please tick all that apply)

$\square$ age

$\square$ gender

$\square$ postcode

$\square$ nationality

$\square$ ethnicity

$\square$ sexual orientation

$\square$ Others (please specify)

$\square$ marital status

$\square$ disability

dependents

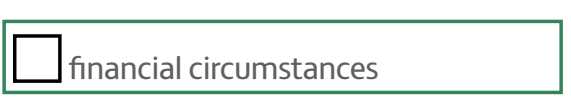

$\square$ employment status

$\square$ educational qualifications $\square$ social security benefit/s received

$\square$ immigration status

$\square$ housing status

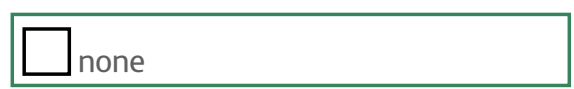


Q30 If you gather data on client financial circumstances, how do you gather this? (please tick all that apply)

$\square$ client signs an informal declaration that they cannot afford to pay for legal support

receipt of defined social security benefits

application/s for defined social security benefits employment status

housing status

proof of income through bank/pay statements

Others (please specify)

Q31 Do you limit clinic services to those with reduced financial circumstances?

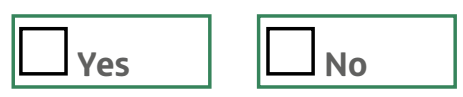

If Yes Is Selected, Then Skip To If yes, why? (e.g. to ensure limited ... If No Is Selected, Then Skip To If no, why? (e.g. too difficult to as...

Q32 If no, why? (e.g. too difficult to assess; assumption that clients with clinic-focused problems will have reduced financial circumstances; not relevant to the service being provided; etc.) 
Q33 If yes, why? (e.g. to ensure limited resources are well targeted; to avoid competing with private practice; to meet defined objective for the clinic; etc.)

Q34 Do you have a case selection to select/reject clinic cases?

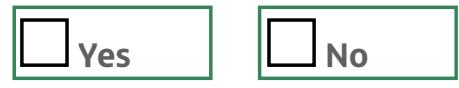

If Yes Is Selected, Then Skip To If yes, what is your case selection c...

If No Is Selected, Then Skip To If no, why not?

Q35 If If no, why not? Is Not Empty, Then Skip To Do clients self-refer to the clinic?

Q36 If yes, what is your case selection criteria? (e.g. ability to access advice support; ability to pay for professional legal support; area of law; complexity of issue; etc.)

Q37 Why did you chose this criteria? (e.g. to reflect areas of law studies; by agreement with professional partners; to ensure the clinic has the capacity to deliver; etc.) 
Q38 Do clients self-refer to the clinic?

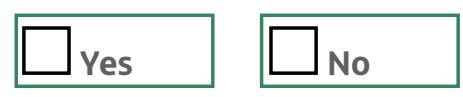

Q39 Do clients get referred to the clinic?

$\square$ Yes $\square$ No

If Yes is Selected, Then Skip To If yes, where are clients referred fr...

If No Is Selected, Then Skip To Does the clinic have a referral crite...

Q40 If yes, where are clients referred from? (please tick all that apply)

$\square$ Solicitors
$\square$ Barristers

$\square$ Independent Advice Agencies (e.g. CAB)

$\square$ Local Authorities

$\square$ Police

$\square$ Health Workers

$\square$ Trade Unions

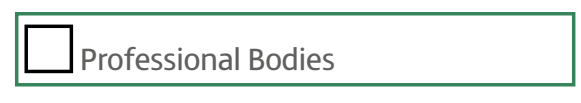

Others (please specify)

Q41 Does the clinic have a referral criteria?

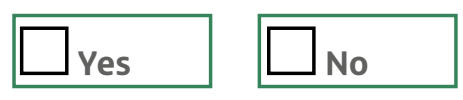

If Yes Is Selected, Then Skip To If yes, what is the referral criteria? If No Is Selected, Then Skip To What other sources of help have clien... $\square$ Government Departments

$\square$ Claims Agencies

$\square$ Housing Associations

$\square$ The media

$\square$ Banks

$\square$ schools

$\square$ Trade Associations

$\square$ Churches $\square$ Students Unions $\square$ Financial Institutions (14)

$\square$ Court Staff
$\square$ Churches 
Q43 What other sources of help have clients accessed prior to coming to the clinic? (please tick all that apply)

$\square$ Solicitors

$\square$ Barristers

$\square$ Independent Advice Agencies (e.g. CAB)

$\square$ Local Authorities

$\square$ Police

$\square$ Health Workers

$\square$ Trade Unions

Professional Bodies

$\square$ Others (please specify) $\square$ Employers

$\square$ Insurance Companies

$\square$ Politicians

$\square$ Social Workers

$\square$ Jobcentres

$\square$ Financial Institutions (14)

$\square$ Court Staff

$\square$ Churches
Government Departments

$\square$ Claims Agencies

$\square$ Housing Associations

$\square$ The media

$\square$ Banks

$\square$ schools

$\square$ Trade Associations

Students Unions

Q43 What are the 3 most common sources of help that your clients access prior to coming to the clinic? (please tick a maximum of three)

\section{$\square$ Solicitors}

$\square$ Barristers

Independent Advice Agencies (e.g. CAB)

$\square$ Local Authorities

$\square$ Police

$\square$ Health Workers

$\square$ Trade Unions

$\square$ Professional Bodies

Others (please specify) $\square$ Employers

$\square$ Insurance Companies

$\square$ Politicians

$\square$ Social Workers

$\square$ Jobcentres

$\square$ Financial Institutions (14)

$\square$ court Staff

$\square$ Churches $\square$ Government Departments

$\square$ Claims Agencies

$\square$ Housing Associations

$\square$ The media

$\square$ Banks

$\square$ Schools

$\square$ Trade Associations

$\square$ Students Unions

\section{Please add any additional comments you think are relevant here.}


Q46 Approximately how many other advice sources will clients typically have accessed before coming to the clinic?

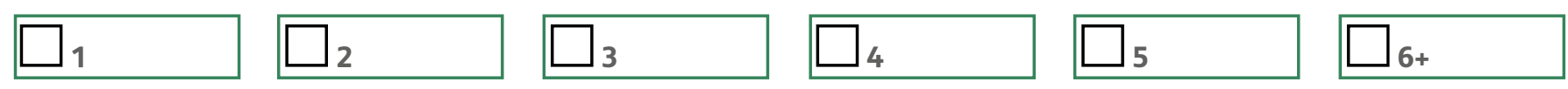

Q47 At what points in their advice -seeking/dispute resolution journey are clients contacting the clinic? (please tick all that apply)

$\square$ as soon as the problem arises

after they have made some initial attempts to resolve the problem

as soon as the client knows they may have a legal deadline to meet

when the time limits for resolving the dispute are restricted (e.g. when court/tribunal hearings are imminent)

$\square$ when the client is at crisis point

$\square$ others (please specify)

Q48 Please add any additional comments you think are relevant here.

Q49 What intellectual barriers do your clients face in resolving their legal problem/s?

(please tick all that apply)

understanding the decision making process

$\square$ understanding if decisions/problems can be challenged

understanding how decisions/problems can be challenged

understanding written information on legal entitlements and processes

understanding the reasons why decisions have been made

knowing how to complete relevant documentation

understanding the legal formalities, including language and procedures

others (please specify) 
Q50 What practical barriers do your clients face in resolving their legal problem/s?

(please tick all that apply)

knowing where to get relevant documents (e.g. social security benefit appeal forms)

knowing where to go for help/advice

ong waiting times to access sources of help/advice

costs of accessing other sources of help/advice

costs of securing expert/supportive evidence

$\square$ physical access to sources of help/advice

English language barriers

$\square$ others (please specify)

Q51 What emotional barriers do your clients face in resolving their legal problem/s?

(please tick all that apply)

$\square$ anxiety

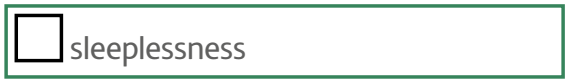

$\square$ lack of confidence

$\square$ stress

$\square$ depression

$\square$ fear

$\square$ anger

$\square$ frustration

Others (please specify)

Q52 Please add any additional comments you think are relevant here.

Q53 How do clients know about the clinic? 


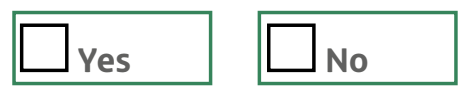

\section{If No Is Selected, Then Skip To Do clients understand what the clinic...}

Q55 If yes, how does the clinic advertise it's services? (e.g. posters; leaflets; development of referral network; local radio; clinic/Law School social media accounts; website; etc.)

Q56 Which of these forms of advertising is most successful in reaching potential clients?

Q57 Do clients understand what the clinic does?

$\square$ fully understand

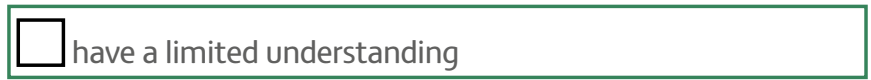

have a reasonable but incomplete understanding

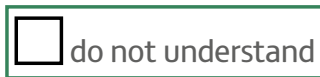

Q58 What are the most common misperceptions that clients have about clinic services? 
Q59 Do clients have concerns about relying on legal advice from law students?

$\square$ No concerns Identified

$\square$ Yes (please specify)

Q60 Do you collect client feedback?

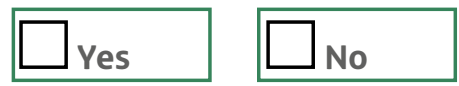

Q61 If yes, what is the purpose of collecting this feedback?

(please tick all that apply)

$\square$ to improve service provision

$\square$ to let students know what clients think of their work to identify need

to measure impact

Others (please specify)

Q62 Why was your clinic set up? 
Q63 What are the objectives of the clinic? (please tick all that apply)

to improve student employability

to develop professional capacity in law students

to deliver access to justice

to meet unmet legal need

to foster a sense of social justice among law students

to raise student awareness of the impact of legal problems

to improve client participation in legal processes

others (please specify)

Q64 Please rank your clinic objectives with 5 being the most important and 0 being the least important

\begin{tabular}{|c|c|c|c|c|c|c|}
\hline & 0 & 1 & 2 & 3 & 4 & 5 \\
\hline $\begin{array}{l}\text { To improve student employability } \\
\text { student employability }\end{array}$ & & & & & & \\
\hline $\begin{array}{l}\text { To develop professional capacity in } \\
\text { law students }\end{array}$ & & & & & & \\
\hline To deliver access to justice & & & & & & \\
\hline To meet unmet legal need & & & & & & \\
\hline $\begin{array}{l}\text { To foster a sense of social justice } \\
\text { among law students }\end{array}$ & & & & & & \\
\hline $\begin{array}{l}\text { To raise student awareness of the } \\
\text { impact of legal problems }\end{array}$ & & & & & & \\
\hline To assist local communities & & & & & & \\
\hline $\begin{array}{l}\text { To improve client participation in } \\
\text { legal processes }\end{array}$ & & & & & & \\
\hline Other & & & & & & \\
\hline
\end{tabular}

Q65 Do you feel that a university Law School should be an access to justice provider?

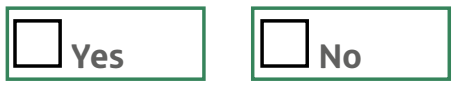

If Yes Is Selected, Then Skip To If yes, why?If No Is Selected, Then Skip To If no, why not? 


\section{Q66 If yes, why? (please tick all that apply)}

$\square$ important part of legal learning

important part of Law School/university ethos

$\square$ good use of student talent $\square$ good pedagogic initiative

there is a legal need for it

$\square$ there is a moral obligation to provide assistance

Others (please specify)

Q67 If no, why not? (please tick all that apply)

$\square$ too time/resource intensive

incompatible with other priorities

access to justice services should be the state's responsibility $\square$ interferes with work of private sector lawyers

too much risk involved

Others (please specify)

Q68 Do you consider the clinic to be an access to justice provider?

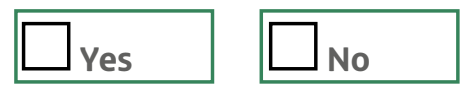

Q69 Please explain why: 


Access to Justice through University Law Clinics


Ulster

University

Published by Ulster University Law School.

ISBN: 978-1-85923-268-2

Publication price: $£ 4.95$ 